\title{
A BREATH OF FRESH AIR 2015 / UNE BOUFÉE D'AIR FRAIS 2015 ABSTRACTS / RÉSUMES
}

\section{Asthma}

01 - CRC2015-059

OBJECTIVE MEASURES OF ASTHMA, SUBJECTIVE DISTRESS, AND PHYSIOLOGICAL RESPONSES OF ASTHMA PATIENTS WITH AND WITHOUT PANIC DISORDER DURING METHACHOLINE CHALLENGE

$\underline{\text { SL Bacon }}^{1,2}$, M Boudreau ${ }^{1,3}$, KL Lavoie $^{1,3}$, A Elhalwi ${ }^{1,2}$, J Sayegh-Smith ${ }^{1,4}$, C Lemiere ${ }^{1,4}$, K Maghni ${ }^{1,4}$

${ }^{1}$ Montreal Behavioural Medicine Centre, Montreal, Hôpital du Sacré-Cœur de Montréal; ${ }^{2}$ Department of Exercise Science, Concordia University; ${ }^{3}$ Department of Psychology, University of Quebec at Montreal (UQAM); ${ }^{4}$ Department of Medicine, Universite de Montreal, Montreal, QC

RATIONALE: Panic disorder (PD) has been shown to be associated with worse asthma outcomes in individuals with asthma, but the psychophysiological mechanisms underlying this association remain unclear. Some theories suggest that asthmatics with PD have worse underlying asthma severity and some argue that they simply report more symptoms based on their tendency to catastrophize bodily sensations.

METHODS: A total of 39 patients (19 with and 20 without PD) with physician-diagnosed asthma underwent standard metacholine challenge testing (MCT). Demographic and medical/asthma history information was collected at baseline. Pre and post MCT patients completed the Panic symptom scale (PSS), the Modified Borg Scale (MBS), and the Subjective distress visual analogue scale (SD-VAS). Heart rate (HR), systolic, and diastolic blood pressure (SBP/DBP) were recorded pre, during, and post MCT. RESULTS: There were no differences in PC20 values between asthmatics with and without $P D(F=0.21, p=0.652)$. $P D$ patients had a higher number of panic symptoms (from the PSS) at post-test compared to those without $\mathrm{PD}([\mathrm{M}(\mathrm{SD})] \mathrm{PD}$ pre $=2.21(2.42), \mathrm{PD}$ post $=5.00(3.32)$; non- $\mathrm{PD}$ pre $=$ 0.75 (1.07), non-PD post $=2.25$ (1.89): $\mathrm{F}=5.05, \mathrm{p}=0.031)$. There were no differences in MBS $(F=0.70, p=0.407)$, SD-VAS anxiety $(F=0.36, p=0.554)$, SD-VAS worry $(\mathrm{F}=0.84, \mathrm{p}=0.366), \mathrm{HR}(\mathrm{F}=0.06, \mathrm{p}=0.805)$, SBP $(\mathrm{F}=0.49$, $\mathrm{p}=0.487)$, or $\mathrm{DBP}(\mathrm{F}=0.01, \mathrm{p}=0.942)$ between $\mathrm{PD}$ and non-PD patients. CONCLUSIONS: Results suggest that having PD is associated with increased subjective responses during MCT, with no impact on objective measures of asthma. Future research should focus on the potential impact of these increased panic attack-like symptoms on long-term asthma care and if intervening on them influences outcomes such as emergency room visits. Financial Support: SLB and KLL were supported by CIHR and FRQS salary awards.

\section{2 - CRC2015-051}

THE IMPACT OF HEALTH CARE USE ON THE DEVELOPMENT OF MOOD DISORDERS IN PATIENTS WITH ASTHMA

M Béland ${ }^{1,2,3}$, SL Bacon ${ }^{1,2,3}$; KL Lavoie ${ }^{2,3,4}$

${ }^{1}$ Concordia University; ${ }^{2}$ Montreal Behavioral Medicine Centre;

${ }^{3}$ Hôpital du Sacré-Coeur de Montréal; ${ }^{4}$ Université du Québec à

Montréal, Montreal, QC

RATIONALE: Studies have shown that the prevalence of mood disorders (MD) is higher in asthmatics than the general population. A recent study has looked at what factors predict the development of MD in people with asthma and found that non-asthma hospitalization was a significant predictor. The aim of this study was to further investigate the impact of health care use on the development of MD in patients with asthma.

METHODS: 495 adults with confirmed asthma and no baseline MD were recruited. Patients completed a questionnaire pack including sociodemographic, medical history, and psychological measures, followed by a brief psychiatric interview. After an average of 4.3 years, the psychiatric interview was re-administered. Univariate logistic regressions were conducted for each potential predictor (ie, non-asthma hospitalization, asthma hospitalizations, asthma emergency visits) and those with a $p<0.15$ for the Waldtest were included in a final multivariate logistic regression.
RESULTS: The two hospitalization variables were included in the final model, though only 1 predictor remained significant. Patients who were hospitalized for a non-asthma event during the 12 months prior to baseline were two times more likely to have a $\mathrm{MD}$ at follow-up $(\mathrm{OR}=2.16 ; 95 \% \mathrm{CI}$ $=0.02-2.16)$ than those who were not hospitalized.

CONCLUSION: These findings reinforce the idea that non-asthma hospitalizations have a long term impact on the development of MD in asthma patients. One possible explanation for these findings is that prior hospitalization could be the beginning of more hospitalizations in the future, which could in turn lead to, or facilitate, the development of an MD.

Financial Support: Project funded by SSHRC. Drs Bacon and Lavoie also received salary support from CIHR and FRQS.

\section{$03 \cdot$ CRC2015-026} AIRWAY RESPONSIVENESS TO MANNITOL DECREASES
24 HOURS AFTER ALLERGEN INHALATION CHALLENGE BE Davis $^{1,2}$, DO Amakye ${ }^{2}$, DW Cockcroft ${ }^{1,2}$

${ }^{1}$ Department of Medicine, Division of Respirology, Critical Care and Sleep Medicine; ${ }^{2}$ Department of Physiology, University of Saskatchewan, Saskatoon, SK

RATIONALE : Airway responsiveness to indirect stimuli correlates positively with airway inflammation. Allergen inhalation challenge is associated with an influx of inflammatory cells and an increase in bronchial airway response sensitivity to methacholine at 3 hours and 24 hours post allergen challenge. We recently documented a loss in airway responsiveness to mannitol 3 hours after allergen challenge which may have been due to cross refractoriness. We hypothesized that airway responsiveness to mannitol would increase 24 hours after allergen challenge.

METHODS: Eleven individuals with mild atopic asthma completed standardized allergen bronchoprovocation testing on two separate occasions separated by at least two weeks. In random order, methacholine or mannitol challenges were performed 24 hours pre and 24 hours post allergen challenge. Levels of fractional exhaled nitric oxide (FeNO) were also measured pre and post allergen challenge.

RESULTS: Airway responsiveness to methacholine increased 24 hours post allergen challenge; the geometric mean methacholine PC20 decreased from $5.9 \mathrm{mg} / \mathrm{mL}$ to $2.2 \mathrm{mg} / \mathrm{mL}$ ( $\mathrm{p}=0.011$ ). FeNO levels were significantly increased at this same time-point $(\mathrm{p}=0.01)$. Conversely, allergen exposure decreased airway responsiveness to mannitol; geometric mean dose response ratio was significantly higher after allergen exposure $(57 \mathrm{mg} / \%$ fall to $147 \mathrm{mg} / \%$ fall; $\mathrm{p}=0.028)$. FeNO levels were also increased but not significantly ( $\mathrm{p}=0.05$ ) (Figure 1$)$.

CONCLUSIONS: Allergen induced changes in airway responsiveness to direct and indirect stimuli are markedly different. The loss in responsiveness to mannitol is likely not explainable by a refractory state. The effect(s) of allergen exposure on airway responsiveness to indirect acting stimuli requires further investigation.

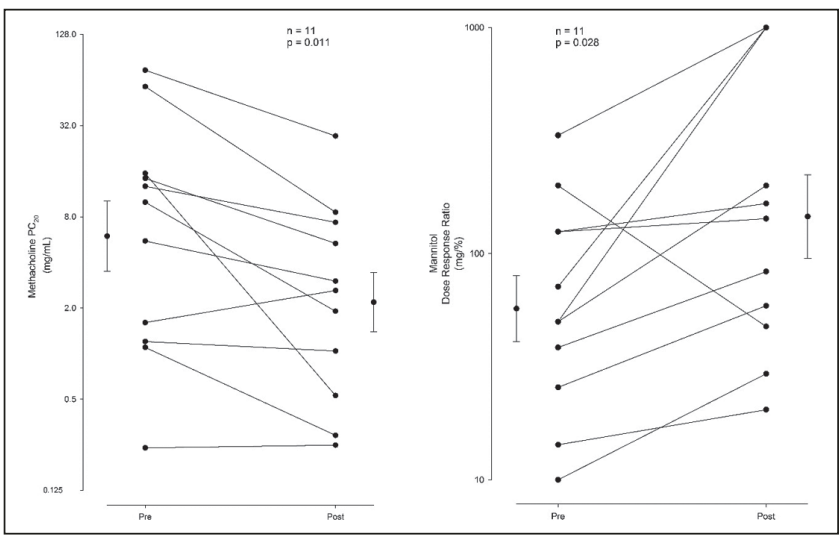

Figure 1) Allergen induced changes in airway responsiveness to methacholine (left) and mannitol (right) at 24 hours post allergen inhalation challenge 
Financial Support: Unfunded; mannitol kits supplied by Pharmaxis.

Conflicts of Interest: None to declare.

Registration: clinicaltrials.gov NCT 01699594

04 - CRC2015-039

SELF-EFFICACY, MOTIVATION AND HEALTHCARE PROVIDER AUTONOMY SUPPORT: IMPACT ON ASTHMA MEDICATION ADHERENCE

AI Dragomir $^{1,2}$, SL Bacon ${ }^{1,3}$, G Moullec ${ }^{1,4}$, L Blais ${ }^{1,5}$, C Laurin ${ }^{1}$, KL Lavoie ${ }^{1,2}$

${ }^{1}$ Montreal Behavioural Medicine Centre, Hôpital du Sacré-Coeur de Montréal; ${ }^{2}$ Department of Psychology, Université du Québec à Montréal; ${ }^{3}$ Department of Exercise Science, Concordia University, Montreal; ${ }^{4}$ Department of Psychology, Université du Québec en Outaouais, Hull; ${ }^{5}$ Faculty of Pharmacy, Université de Montréal, Montréal, QC

RATIONALE: Achieving asthma control relies heavily upon daily adherence to medication, yet adherence to inhaled corticosteroids (ICS) has been shown to be as low as $32 \%$ in patients with asthma. Adherence to ICS may be influenced by motivational factors including self-efficacy, autonomous motivation, and perceived autonomy support from health care providers. The purpose of this study was to examine associations between self-efficacy, levels of autonomous motivation, and perceived autonomy support from health care providers on baseline adherence levels among adult patients with asthma.

METHODS: Forty-four poorly controlled (mean [SD] ACQ = 1.8 [0.9]) adult asthmatics (mean [SD] age $=53$ [15] years, 66\% women) completed assessments of self-efficacy (Perceived Compentence Scale, PCS), autonomous motivation (Treatment Self-Regulation Questionnaire), and perceived autonomy support from health care providers (Health Care Climate Questionnaire, HCCQ) at baseline as part of a study to assess a motivational communication intervention for medication adherence. General linear models adjusting for age, sex and levels of asthma control were used to assess associations between baseline adherence and the above variables.

RESULTS: On average (SD), patients filled 33 (23) \% of their prescriptions in the previous year. After adjustment for covariates, only greater perceived autonomy support from health care providers was found to be significantly associated with baseline ICS adherence among asthmatics $(\mathrm{b}=5.8, \mathrm{t}=2.21, \mathrm{p}=0.03)$.

CONCLUSION: Results indicate that the extent to which asthmatics perceive their healthcare providers as being autonomy supportive (versus controlling) in providing treatment may be an important determinant of increased ICS adherence. These findings lend support for increased use of motivational approaches by health care professionals and shared-decision making as a means to optimize medication adherence in patients with asthma. Financial Support: KLL: GSK Investigator-initiated grant; FRQS and CIHR salary awards. SLL: FRQS and CIHR salary award.

\section{$05 \cdot$ CRC2015-052}

\section{EVOLUTION OF ALLERGIC BRONCHOPULMONARY} ASPERGILLOSIS IN CYSTIC FIBROSIS

V Labossière $^{1}$, F Tremblay ${ }^{2}$, A Lavoie ${ }^{2}$, M Sylviet-Carricart ${ }^{2}$, C Bergeron ${ }^{2}$

${ }^{1}$ Faculté de médecine de l'Université de Montréal; ${ }^{2}$ Centre hospitalier de I'Université de Montréal - Hôtel-Dieu de Montréal, Montréal, QC

INTRODUCTION: Allergic bronchopulmonary aspergillosis (ABPA) is a common complication among cystic fibrosis (CF) and is mainly treated with systemic corticosteroids (SCS). The present study aims to determine the prevalence of ABPA, the evolution and the therapeutic approach within the CF cohort of the CHUM.

METHODS: During the period 2010 to 2014, a file review of CF patients with ABPA was performed, as well as for a control CF group without ABPA. The control group was matched for: age, sex, $\mathrm{FEV}_{1}$, mutation and Pseudomonas colonization. Diagnosis criteria for ABPA, pulmonary function, exacerbations and treatments were analysed.
RESULTS: Within the total cohort of 314 CF, 22 were identified as ABPA patients, leading to a $\%$ prevalence. Within the ABPA group, the average total IgE was $3490 \mathrm{KUI} / \mathrm{L}$ with SCS and 4211 without SCS, specific Aspergillus-IgE were identified in 20 patients, only 7 patients had performed an Aspergillus skin prick test (all positives), 73\% were colonized by Aspergillus fumigatus, and a radiological deterioration was observed in all. The average $\mathrm{FEV}_{1}$ decline was of $-18.2 \mathrm{~mL} /$ year in $\mathrm{ABPA}$, and of $-61.4 \mathrm{~mL} /$ year in control. $77 \%$ of all ABPA patients were treated with SCS, $64 \%$ with antifungal treatment and $27 \%$ with anti-IgE therapy. Therapeutic compliance was of $73 \%$ (ABPA) and $55 \%$ (control). ABPA and control patients presented a respective average of 3.5 and 2.5 exacerbations/year, and 8 exacerbations/year in the subgroup of ABPA patients before starting anti-IgE. Anti-IgE therapy revealed a diminution of $45 \%$ of the exacerbations' rate, led to a complete (2) and a partial (1) withdrawal of SCS, and $\mathrm{FEV}_{1}$ kept stable.

CONCLUSION: ABPA in CF is a prevailing condition causing $1,4 \mathrm{X}$ more exacerbations but also, oddly, a slower $\mathrm{FEV}_{1}$ decline, which may ensue from the effect of SCS therapy, anti-IgE treatment and a better therapeutic compliance.

Financial Support: Education grant without restriction from Novartis.

\section{$06 \cdot$ CRC2015-021}

\section{INVESTIGATING THE QUANTITATIVE RELATIONSHIP BETWEEN BODY MASS INDEX AND AIRWAY HYPERRESPONSIVENESS IN ADULTS WITH ASTHMA}

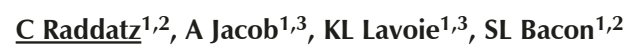

${ }^{1}$ Montreal Behavioural Medicine Centre, Hôpital du Sacré-Coeur de Montreal; ${ }^{2}$ Department of Exercise Science, Concordia University; ${ }^{3}$ Department of Psychology, Université du Quebec à Montreal, Montreal, QC

RATIONALE: There has been an observed increase of asthma prevalence and incidence within obese adult populations suggesting a physiological link between the two diseases that has yet to be fully determined. Obesity, independent of asthma, can cause asthma-like symptoms; therefore the measurement of airway-hyperresponsiveness as an objective marker of asthma is an important variable to consider when looking at the obesityasthma relationship. The objective of the present study was to determine if the severity of airway- hyperresponsiveness increases with increasing body mass index (BMI).

METHODS AND RESULTS: Measured BMI values and baseline $\mathrm{PC}_{20}$ values, from standard methacholine testing, were analyzed for 69 patients with objectively diagnosed asthma and 50 non-asthma patients, all of who were examined for occupational asthma. In the asthma group, $\mathrm{PC}_{20}$ values increased with increasing BMI $(\beta[S E]=0.04$ [0.02], $p=0.03)$, such that airway-hyperresponsiveness severity decreased with increasing BMI. There was no significant relationship observed between $\mathrm{PC}_{20}$ values and $\mathrm{BMI}$ in the non-asthma group ( $\beta[S E]=-0.009[0.01], p=0.5)$.

CONCLUSIONS: These finding may present clinical implications for the assessment and diagnosis of asthma in patients with high BMI. The decrease in asthma severity with higher BMI may indicate that weight-gain in patients with asthma may not increase asthma severity. However, the systematic assessment of the relationship between BMI and AHR following weight changes needs to be done. Additionally, the absence of an observed relationship between $\mathrm{PC}_{20}$ values and $\mathrm{BMI}$ in the non-asthma group may indicate that BMI does not significantly impact airwayhyperresponsiveness without pre-existing asthma.

Financial Support: KLL and SLB are supported by CIHR and FRQS salary awards.

$07-$ CRC2015-036

PREDICTORS OF HAVING PANIC ATTACK-LIKE SYMPTOMS IN ASTHMA PATIENTS UNDERGOING A METHACHOLINE CHALLENGE TEST

Sayegh-Smith, M Boudreau, SL Bacon, KL Lavoie

Research Centre, Hôpital du Sacré-Coeur de Montréal, Montreal, QC RATIONALE: When asthma and panic disorder (PD) are both present in an individual, the prognostic is poorer, with a higher hospitalization rate 
and medication dosage for the same severity of asthma. Therefore, it is of interest to identify those asthmatics that are more prone to panic attacks. METHODS: In a cohort of asthmatic patients undergoing a methacholine challenge test to provoke airway hyperresponsiveness (AHR), we investigated the predictors differentiating the subjects having a panic attack from those who do not (Panic Symptom Scale, PSS). A total of 37 patients (18 with and 19 without PD) between 18 and 70 years old were recruited from an outpatient asthma clinic, from 2011 to 2013 at Sacré-Coeur Hospital of Montreal. All patients had a past positive methacholine challenge and were non-smoking.

RESULTS: Seven subjects out of 37 had panic attack-like symptoms according to the PSS. Univariate logistic regressions showed that taking anxiolytics (OR [95\% CI] = 21.8 [1.8-263.1]), having a higher frequency of health service use (emergency visits and hospitalizations) in the past year (OR [95\% CI] $=14.5$ [1.1-198.8] per event), and having higher hyperventilation symptoms (HVQ questionnaire: OR [95\% CI] $=1.05$ [1.01-1.10] per unit) were associated with a greater probability of having panic attacklike symptoms during methacholine challenge. Non-significant trends for PD $(p=0.055)$, antidepressant use $(\mathrm{p}=0.06)$ and low scores on the Asthma Quality of Life Questionnaire ( $\mathrm{p}=0.08$ ) were observed, though no associations were found for sex, age, body mass index, education level, employment status, ethnicity, cohabitation, past smoking, severity of AHR, dose of inhaled corticosteroid, weekly inhalations of salbutamol, or scores on the Asthma Control Questionnaire.

CONCLUSION: This study showed that anxiolytic use, higher health service use, hyperventilation, and marginally - a diagnosis of PD - are associated with an increased risk of panic attack-like symptoms during AHR.

Financial Support: None.

\section{Chronic Obstructive Pulmonary Disease} (COPD)

08 - CRC2015-008

CHARACTERIZATION OF MORPHOLOGICAL PHENOTYPES OF COPD SUBJECTS BY MDCT SCAN AND THEIR RELATIONSHIP TO EXERCISE PHYSIOLOGY AND SYMPTOM LIMITATION

M Brosseau ${ }^{1}$, D Jensen ${ }^{1}$, H Coxson ${ }^{2}$, B Smith ${ }^{1}$, J Bourbeau ${ }^{1}$

${ }^{1}$ Respiratory Epidemiology and Clinical Research Unit, Montreal Chest Institute, McGill University Health Centre, Montreal, QC; ${ }^{2}$ Vancouver General Hospital, University of British Columbia, Vancouver, BC

RATIONALE: GOLD grade used to define COPD severity reflects poorly disease heterogeneity. CT permits in vivo detection of emphysema and airway lumen narrowing - both contributors to airflow limitation. We hypothesize that CT morphological phenotypes will be associated with distinct cardiopulmonary exercise abnormalities, including maximum work rate $\left(\mathrm{WR}_{\max }\right)$, inspiratory reserve volumes (IRV), and reasons for ending exercise.-

METHODS: This cross-sectional study recruited 73 smokers with stable COPD (post-bronchodilator $\mathrm{FEV}_{1} / \mathrm{FVC}<0.70$ ), 40 to 80 years of age, with dyspnea. Emphysema was quantified as the percent emphysema950HU, and airway lumen areas measured in cross-section on inspiratory thoracic CT. Constant-load exercise testing was performed at $75 \%$ of $\mathrm{WR}_{\max }$, with measurements of IRV at rest and at end-exercise, as well as the reason for stopping. Linear regression adjusted for age, gender, height, ideal body weight, and smoking status.

RESULTS: Among 66 participants completing CT and exercise testing, mean age was $66 \pm 8$ years and GOLD grades $1-4$. Lower $\mathrm{WR}_{\max }$ was associated with higher percent emphysema-950HU $(p=0.0003)$ and smaller mean airway lumen area $(p=0.0003)$, significant after adjustment for GOLD grade $(\mathrm{p} \leq 0.02)$. Percent emphysema $950 \mathrm{HU}$ was associated with lower IRV at rest and at end-exercise $(\mathrm{p} \leq 0.004)$ but not with change in IRV. Smaller mean lumen area was associated with lower IRV at rest and smaller change during exercise $(\mathrm{p} \leq 0.004)$. Percent emphysema950HU and mean airway lumen area did not differ according to the reason for stopping.-
CONCLUSION: CT lung morphology in COPD is associated with lower exercise capacity independent of GOLD severity. Percent emphysema950HU is associated with lower IRV throughout exercise, whereas smaller airway lumen size with dynamic reduction in IRV. The use of CT lung phenotyping may have application in further individualizing treatment in COPD.

Financial Support: GlaxoSmithKline Canada Ltd.

\section{9 • CRC2015-034}

\section{THE IMPACT OF STEPWISE WITHDRAWAL OF INHALED CORTICOSTEROIDS ON EXACERBATIONS IN COPD PATIENTS RECEIVING DUAL BRONCHODILATION: WISDOM STUDY}

C Charbonneau ${ }^{1}$ (presenting on behalf of $\mathrm{H} \mathrm{Magnussen}^{2}$ ), $\mathrm{P} \mathrm{Chane}^{3}$, R Dahl $^{4}$, M Decramer ${ }^{5}$, B Disse ${ }^{6}$, H Finnigan ${ }^{7}$, A Kirsten ${ }^{2}$, R Rodriguez-Roisin ${ }^{8}$, K Tetzlaff ${ }^{6,9}$, L Towse ${ }^{10}$, H Watz $^{2}$, EFM Wouters ${ }^{11}$, PMA Calverley ${ }^{12}$

${ }^{1}$ Medical Affairs, Boehringer Ingelheim (Canada) Ltd, Burlington, ON; ${ }^{2}$ Pulmonary Research Institute at Lung Clinic Grosshansdorf, Airway Research Center North, Grosshansdorf, Germany; ${ }^{3}$ Service de Pneumologie, Hôpital Nord, Marseille, France; ${ }^{4}$ Allergy Centre, Odense University Hospital, Odense, Denmark; ${ }^{5}$ Department of Respiratory Diseases, University of Leuven, Leuven, Belgium; ${ }^{6}$ Respiratory Diseases, Boehringer Ingelheim Pharma GmbH \& Co KG, Ingelheim, Germany; ${ }^{7}$ Biometry and Data Management Department, Boehringer Ingelheim (UK), Berkshire, United Kingdom; ${ }^{8}$ Servei de Pneumologia (ICT), Hospital Clínic-IDIBAPS-CIBERES, Barcelona, Spain; ${ }^{9}$ Department of Sports Medicine, University of Tübingen, Tübingen, Germany; ${ }^{10}$ Clinical Research Department, Boehringer Ingelheim (UK), Berkshire, United Kingdom;

${ }^{11}$ Department of Respiratory Medicine, Maastricht University Medical Centre (MUMC+), Maastricht, Netherlands; ${ }^{12}$ Institute of Ageing and Chronic Disease, University Hospital Aintree, Liverpool, United Kingdom

BACKGROUND: Although guidance recommends ICS for prevention of recurrent COPD exacerbations, there is still uncertainty about the benefits of ICS.

OBJECTIVE: To evaluate the effects of stepwise withdrawal of ICS in patients (pts) with GOLD 3-4 COPD and a history of exacerbation who are treated with LAMA+LABA.

METHODS: WISDOM (NCT00975195) was a 12-month, double-blind, parallel-group, active controlled study in which all pts received triple therapy (tiotropium $18 \mu \mathrm{g}$ QD, salmeterol $50 \mu \mathrm{g}$ BID and fluticasone $500 \mu \mathrm{g}$ BID) for a 6-week run-in period. Pts were randomised 1:1 to continue triple therapy or stepwise withdrawal of ICS over 12 weeks (dose reduction every 6 weeks). Primary end point (time to first moderate or severe on-treatment exacerbation) is reported here.

RESULTS: 2485 pts were treated (2049 male); mean age was 63.8 years and mean baseline $\mathrm{FEV}_{1}$ was $0.975 \mathrm{~L}$ (34.2\% predicted). ICS withdrawal was non-inferior to continued ICS for time to first moderate or severe ontreatment COPD exacerbation (hazard ratio 1.058; upper limit of the 95\% CI below the prespecified non-inferiority margin of 1.2 [0.941, 1.189]). No significant safety signals were identified.

CONCLUSIONS: In pts with GOLD 3-4 COPD receiving dual bronchodilation, exacerbation risk is non-inferior with ICS withdrawal compared to ICS therapy.

Financial Support: Boehringer Ingelheim. Previously presented at ERS 2014 in Munich, Germany. 


\section{0 - CRC2015-033}

EFFECTS OF 12 WEEKS OF ONCE-DAILY TIOTROPIUM AND OLODATEROL FIXED-DOSE COMBINATION ON EXERCISE ENDURANCE IN PATIENTS WITH COPD

$\underline{\mathrm{L} \mathrm{Guo}}^{1}$ (presenting on behalf of $\mathrm{F} \mathrm{Maltais}{ }^{2}$ ), JBG Iturri ${ }^{3}$, A Kirsten ${ }^{4}$, D Singh $^{5}$, A Hamilton ${ }^{6}$, K Tetzlaff ${ }^{7,8}$, Y Zhao ${ }^{9}$, R Casaburi ${ }^{10}$

${ }^{1}$ Medical Affairs, Boehringer Ingelheim (Canada) Ltd., Burlington, Canada; ${ }^{2}$ Centre de Recherche, Institut Universitaire de Cardiologie et de Pneumologie de Québec, QC; ${ }^{3}$ Respiratory Function, BioCruces Health Research Institute, Barakaldo, Spain; ${ }^{4}$ Pulmonary Research Institute at Lungclinic Grosshansdorf, Airway Research Center, Grosshansdorf, Germany; ${ }^{5}$ Medicines Evaluation Unit, University of Manchester, Manchester, United Kingdom; ${ }^{6}$ Medical, Boehringer Ingelheim, Burlington, Canada; ${ }^{7}$ Respiratory Diseases, Boehringer Ingelheim Pharma GmbH \& Co. KG, Ingelheim, Germany; ${ }^{8}$ Department of Sports Medicine, Medical Clinic V, University of Tübingen, Tübingen, Germany; ${ }^{9}$ Biostatistics, Boehringer Ingelheim Pharmaceuticals Inc, Ridgefield; ${ }^{10}$ Los Angeles Biomedical Research Institute, Harbor-UCLA Medical Center, Los Angeles, CA, USA

BACKGROUND: Both tiotropium $(\mathrm{T})$ and olodaterol $(\mathrm{O})$ monotherapies improve exercise endurance in patients with chronic obstructive pulmonary disease (COPD).

OBJECTIVE: To evaluate the effects of $\mathrm{T}+\mathrm{O}$ fixed-dose combination on exercise endurance in patients with GOLD 2-3 COPD after 12 weeks. METHODS: TORRACTO (NCT01525615) was a 12-week, doubleblind, parallel-group, placebo-controlled, Phase III study. Patients with GOLD 2-3 COPD received T+O (5/5 or 2.5/5 $\mu$ g) once daily via Respimat Soft Mist inhaler, or placebo. Primary end point was endurance time (ET) during constant work-rate cycle ergometry to symptom limitation after 12 weeks. ET during endurance shuttle walking (ESW) to symptom limitation after 12 weeks was also assessed in a subset of 165 patients. Other end points included pre-exercise inspiratory capacity (IC).

RESULTS: 404 patients (269 men) were randomised (full analysis set $\mathrm{n}=385$ ). Mean post-bronchodilator $\mathrm{FEV}_{1}$ was $1.66 \mathrm{~L}$ (58.6\% predicted). After 12 weeks, geometric mean ET during constant work rate cycle ergometry increased by $14 \%$ with $\mathrm{T}+\mathrm{O}$ FDC $5 / 5 \mu \mathrm{g}$ versus placebo $(\mathrm{p}=0.02)$ and by $9 \%$ with $\mathrm{T}+\mathrm{O}$ FDC $2.5 / 5 \mu \mathrm{g}(\mathrm{p}=0.14)$ versus placebo. In the ESW subset $(n=165)$, increases in ET during ESW were observed for both $\mathrm{T}+\mathrm{O}$ doses vs placebo after 12 weeks ( $21 \%$ increase, nominal $\mathrm{p}=0.06$ for each dose). Both $\mathrm{T}+\mathrm{O}$ doses increased pre-exercise IC vs placebo (nominal $\mathrm{p}<0.0005)$ after 12 weeks. No safety concerns were identified. CONCLUSIONS: $\mathrm{T}+\mathrm{O} 5 / 5 \mu \mathrm{g}$ improved ET during cycle ergometry vs placebo.

Study supported by Boehringer Ingelheim. Previously presented at ERS 2014 in Munich, Germany.

Financial Support: Boehringer Ingelheim. Previously presented at ERS 2014 in Munich, Germany
11 - CRC2015-032

ONCE-DAILY TIOTROPIUM AND OLODATEROL FIXEDDOSE COMBINATION VIA THE RESPIMAT IMPROVES OUTCOMES VS MONO-COMPONENTS IN COPD IN TWO 1-YEAR STUDIES

A Hamilton ${ }^{1}$, R Buhl'2, E Derom ${ }^{3}$, G Ferguson ${ }^{4}$, F Maltais $^{5}$, E Pizzichini' $^{6}$, J Reid ${ }^{7}$, H Watz ${ }^{8}$, L Groenke', Kay Tetzlaff ${ }^{10}$, L Korducki $^{11}$, H Huisman ${ }^{12}$, SWaitere-Wijker ${ }^{12}$, E Bateman ${ }^{13}$ ${ }^{1}$ Boehringer Ingelheim, Burlington, ON; ${ }^{2}$ Pulmonary Department, Mainz University Hospital, Mainz, Germany; ${ }^{3}$ Ghent University Hospital, Ghent, Belgium; ${ }^{4}$ Pulmonary Research Institute of Southeast Michigan, Livonia, Michigan, USA; ${ }^{5}$ Centre de Recherche, Institut Universitaire de Cardiologie et de Pneumologie de Québec, QC; ${ }^{6}$ NUPAIVA (Asthma Research Centre), Universidade Federal de Santa Catarina, Santa Catarina, Brazil; ${ }^{7}$ Dunedin School of Medicine, University of Otago, Dunedin, New Zealand; ${ }^{8}$ Pulmonary Research Institute at LungClinic Grosshansdorf, Airway Research Center North, Member of the German Center for Lung Research, Grosshansdorf, Germany; ${ }^{9}$ Boehringer Ingelheim Pharma GmbH \& Co. KG, Ingelheim; ${ }^{10}$ Boehringer Ingelheim Pharma GmbH \& Co KG, Ingelheim, Germany and Department of Sports Medicine, Medical Clinic V, University of Tübingen, Tübingen, Germany; ${ }^{11}$ Boehringer Ingelheim Pharmaceuticals Inc, Ridgefield, Connecticut, USA; ${ }^{12}$ Boehringer Ingelheim BV, Alkmaar, the Netherlands; ${ }^{13}$ University of Cape Town Lung Institute, Cape Town, South Africa

INTRODUCTION: Tiotropium (T), a once-daily long-acting muscarinic antagonist, is a well-established first-line maintenance treatment in chronic obstructive pulmonary disease (COPD); olodaterol $(\mathrm{O})$ is a oncedaily long-acting $\beta 2$-agonist that has recently gained approval in several countries. Two Phase III replicate pivotal studies assessed the efficacy and safety of fixed-dose combinations of $\mathrm{T}$ and $\mathrm{O}(\mathrm{T}+\mathrm{O})$ delivered via Respimat Soft Mist inhaler in patients with GOLD Stage 2-4 COPD.

METHODS: Two 52-week, double-blind, parallel-group studies randomised 5162 patients to $\mathrm{O} 5 \mu \mathrm{g}, \mathrm{T} 2.5 \mu \mathrm{g}, \mathrm{T} 5 \mu \mathrm{g}, \mathrm{T}+\mathrm{O} 2.5 / 5 \mu \mathrm{g}$ or $\mathrm{T}+\mathrm{O}$ $5 / 5 \mu \mathrm{g}$. Primary efficacy end points were trough FEV1 response (ie change from baseline), FEV1 area under the curve from 0-3 hours response and SGRQ total score after 24 weeks. Pooled data from the two studies are presented here; lung function from the individual studies will subsequently be provided.

RESULTS: All treatments resulted in clinically relevant improvements in lung function, with significant increases with both $\mathrm{T}+\mathrm{O}$ doses over the individual components $\left(\mathrm{p}<0.001\right.$ for each study). Trough $\mathrm{FEV}_{1}$ responses were $0.055 \mathrm{~L}(\mathrm{O} 5 \mu \mathrm{g}), 0.073 \mathrm{~L}(\mathrm{~T} 2.5 \mu \mathrm{g}), 0.080 \mathrm{~L}(\mathrm{~T} 5 \mu \mathrm{g}), 0.118 \mathrm{~L}(\mathrm{~T}+\mathrm{O}$ $2.5 / 5 \mu \mathrm{g})$ and $0.140 \mathrm{~L}(\mathrm{~T}+\mathrm{O} 5 / 5 \mu \mathrm{g})$. SGRQ total scores improved by $5.1(\mathrm{O}$ $5 \mu \mathrm{g}), 5.7(\mathrm{~T} 2.5 \mu \mathrm{g}), 5.6(\mathrm{~T} 5 \mu \mathrm{g}), 6.2(\mathrm{~T}+\mathrm{O} 2.5 / 5 \mu \mathrm{g})$ and 6.8 points $(\mathrm{T}+\mathrm{O}$ $5 / 5 \mu \mathrm{g})$; differences between $\mathrm{T}+\mathrm{O} 5 / 5 \mu \mathrm{g}$ and $\mathrm{O} 5 \mu \mathrm{g}$ and $\mathrm{T} 5 \mu \mathrm{g}$ were statistically significant $(\mathrm{p}<0.05$ in both cases). All treatments were well tolerated. CONCLUSIONS: $\mathrm{T}+\mathrm{O} 5 / 5 \mu \mathrm{g}$ significantly improved lung function and provided symptomatic benefit over $\mathrm{O} 5 \mu \mathrm{g}$ and $\mathrm{T} 5 \mu \mathrm{g}$.

Financial Support: Boehringer Ingelheim. Previously presented at ERS 2014 in Munich.

\section{2 - CRC2015-018}

SURVEY OF PATIENTS USING AN OSCILLATING POSITIVE EXPIRATORY PRESSURE DEVICE INDICATES IMPROVEMENT IN WELL-BEING AND COMPLIANCE TO THERAPY

H Harkness, C Patrick, J Lefebvre

Trudell Medical International, London, ON

BACKGROUND: Chronic obstructive pulmonary disease (COPD) is characterized by a number of interrelated physiological changes in the lungs, resulting in airflow limitation and chronic inflammatory response which creates excess mucus within the airways. Due to airway damage there is an inability of the lungs to clear excess mucus. Pharmacological treatments have little impact on mucus clearance.

OBJECTIVE: A survey was to be undertaken with patients using a novel device, the Aerobika* Oscillating PEP to determine whether use of the device had any impact on the well-being and quality of life. 
RESULTS: 812 surveys were collected. $90 \%$ of patients had COPD; others patients had bronchiectasis ( $8 \%$ ) and cystic fibrosis (2\%). After approximately 4 weeks use, patients were asked to identify the benefits they experienced from using the device. The following were ranked in terms of priority: easier to clear mucus from lungs, could breathe more deeply, didn't cough as much, overall felt better, not as breathless, better sleep, able to walk easier/farther, and had more energy. The questionnaire demonstrated a high degree of satisfaction with the Aerobika* OPEP by patients, specifically in assisting with mucus clearance and decreased breathlessness which reinforced the findings of a recently presented clinical study (1). In addition, $97 \%$ indicated they would continue to use the device - an exceptionally high acceptance rating leading to better compliance and therapeutic benefit.

CONCLUSION: The results from this patient feedback survey indicate that the Aerobika* OPEP has a high degree of acceptance within the COPD population because it is easy to use, helps clear mucus and reduces feelings of breathlessness.

REFERENCE:

1. Svenningsen S, et al. Oscillating positive expiratory pressure therapy in chronic obstructive pulmonary disease and bronchiectasis. Presented at ERS 2014 (Munich, Germany).

Financial Support: Trudell Medical International.

\section{3 - CRC2015-003}

\section{SELF-CONSCIOUS EMOTIONS IN PATIENTS WITH} CHRONIC OBSTRUCTIVE PULMONARY DISEASE (COPD)

$\underline{\text { SL Harrison }}^{1,2}$, N Robertson ${ }^{3}$, R Goldstein ${ }^{1}$, D Brooks ${ }^{1,2}$

${ }^{1}$ Respiratory Medicine, West Park Healthcare Centre; ${ }^{2}$ Department of Physical Therapy, University of Toronto, Toronto, ON; ${ }^{3}$ School of Psychology, University of Leicester, Leicester, United Kingdom

RATIONALE: Symptoms of anxiety and depression are elevated in patients with COPD. Self-conscious emotions have been documented in patient narratives which appear to negatively impact on psychological morbidity. There is a need to understand the extent to which self-conscious emotions are expressed in patients with COPD.

METHODS: 15 patients with COPD participated in individual interviews exploring self-conscious emotions. Data were coded independently by two researchers and constructs elicited via inductive thematic analysis.

FINDINGS: 6 overarching themes were abstracted: Spectrum of blame accepting personal responsibility for the disease, attempting to justify smoking behaviour and attributing disease to external factors. Concern about the view of others - associated with the visibility of the disease. Minimisation - dismissal of self, related to judgements about self-worth and aging, and dismissal from others. Silence - stoicism and suppression. Worry about the future - related to the progressive nature of COPD and catastrophic cognitions. Grief - loss of the anticipated future and the lifestyle once had.

CONCLUSIONS: Patients recognise COPD to be self-inflicted provoking painful emotions. Embarrassment and shame are coupled with feelings of guilt associated with not wanting to emotionally burden others; yet, patients express desire for compassion and understanding. Reflection on the past and anticipation about the future elicit feelings of grief, frustration and anxiety. Mindfulness therapies which encourage patients to be nonjudgmental about their smoking behavior and draw focus back to the "current' may be beneficial in promoting acceptance and control and reducing elaboration and anxiety.

Financial Support: Funded by the Canadian Respiratory Health Professionals (CRHP) and DB was supported by the Canadian Research Chair.

\section{4 - CRC2015-054}

THE ECONOMIC BURDEN OF COPD IN BRITISH COLUMBIA FROM 2001 TO 2010: A POPULATION BASED STUDY

R Khakban ${ }^{1}$, D Sin ${ }^{2}, \mathrm{R} \mathrm{Ng}{ }^{2}, \mathrm{Z}$ Zafari², B McManus ${ }^{2}$, Z Hollander², M Sadatsafavi ${ }^{3,4}$, J Mark FitzGerald ${ }^{4}$, C Marra $^{5}$

${ }^{1}$ Collaboration for Outcomes Research and Evaluation, Faculty of Pharmaceutical Sciences; ${ }^{2}$ UBC James Hogg Research Centre, Institute for Heart + Lung Health, St Paul's Hospital; ${ }^{3}$ Division of Respiratory Medicine, Faculty of Medicine; ${ }^{4}$ Institute for Heart and Lung Health, University of British Columbia, Vancouver, BC; ${ }^{5}$ School of Pharmacy, Memorial University of Newfoundland, St John's, NL

RATIONALE: The burden of a disease is a complex function of its prevalence, environmental factors, influx of new technologies, and real-world practice patterns. In this ever-changing landscape, up-to-date estimates are required for evidence-informed policy making. The objective of this study was to evaluate the excess cost of COPD and its trends from 2001 to 2010 in British Columbia (BC).

METHODS: We used BC's administrative health data to create a cohort of patients with COPD based on validated case definitions. Patients were matched to a comparison cohort of non-COPD subjects with respect to sex, birth year, local health area, and socio-economic characteristics. Direct medical costs (inflation-adjusted to \$CAD 2010) for COPD and comparison cohorts were calculated based on billing records, and excess costs were estimated by subtracting costs of the comparison group from the COPD group. Costs were categorized as inpatient, outpatient, medication, and community care.

RESULTS: 194,001 and 314,519 individuals constituted the COPD and comparison cohorts, respectively (mean age at entry 69.1, 47.5\% female); average follow-up time was 8.5 years. The excess cost of COPD was $\$ 6,828$ per patient/year. Inpatient, outpatient, medication, and community care costs were responsible for $59 \%, 16 \%, 22 \%$, and $2 \%$ of the excess costs, respectively. The relative share of these cost components remained relatively constant over the last six year of follow-up. Excess costs increased by $\$ 20.0$ million/year $(\mathrm{P}<0.01)$ and per-person costs increased by $\$ 200 /$ year $(\mathrm{P}<0.01)$. CONCLUSIONS: The direct economic burden of COPD has increased significantly between 2001 and 2010 owing to increased prevalence and increased per-patient costs over and beyond the health-care costs of the general population. This should prompt policy makers and researchers to investigate the underlying reasons.

Financial Support: Genome Canada, Genome British Columbia, Genome Quebec, Canadian Institutes of Health Research, Canadian Respiratory Research Network, St Paul's Hospital Foundation \& the PROOF Center of Excellence.

Funding: None.

\section{5 - CRC2015-047}

\section{THE IMPACT OF ANXIETY AND MOOD DISORDERS ON CHRONIC OBSTRUCTIVE PULMONARY DISEASE DEVELOPMENT}

A Moga ${ }^{1,2}$, K Lavoie ${ }^{1,3}$, A Yohannes ${ }^{4}$, R Pelletier ${ }^{1,5}$, SL Bacon ${ }^{1,6}$

${ }^{1}$ Montreal Behavioural Medicine Centre, Hopital du Sacre-Coeur de Montreal; ${ }^{2}$ Department of Physical and Occupational Therapy, McGill University; ${ }^{3}$ Department of Psychology, Universite du Quebec a Montreal, Montreal, QC; ${ }^{4}$ Health Professions Department,

Manchester Metropolitan University, Manchester, United Kingdom; ${ }^{5}$ Department of Medicine, McGill University Health Centre;

${ }^{6}$ Department of Exercise Science, Concordia University, Montreal, QC

BACKGROUND: Mood and anxiety disorders have been associated with the development of a number of non-communicable chronic diseases. chronic obstructive pulmonary disease (COPD), principally defined by a progressive irreversible airflow limitation, is a major cause of morbidity and mortality and a source of substantial economic burden worldwide. It has been shown that comorbid psychiatric disorder in COPD patients is associated with an increased risk of exacerbations and decreased quality of life. Although cigarette smoking is the primary cause of COPD, little is understood about the impact of psychiatric disorders on the development of COPD.

OBJECTIVE: To evaluate the impact of psychiatric disorders, specifically mood and anxiety disorders, compared to no disorders, on COPD development in individuals undergoing an exercise stress test. 
METHODS: Mood and anxiety disorders were assessed among 2390 individuals free of COPD at baseline, using a semi-structured psychiatric interview (PRIME-MD). A diagnosis of COPD was obtained from Quebec provincial databases, using a prospective design. Standard Cox Models were used to assess the main effect of psychiatric disorders on time to COPD diagnosis over the average 8.2 year follow-up.

RESULTS: After adjustment for covariates (ie, age, sex, smoking status, history of major coronary artery disease), individuals with any psychiatric disorder were at increased risks of developing COPD $(\mathrm{RR}=1.57 ; 95 \% \mathrm{CI}$ $1.08-2.28)$ compared to those without psychiatric disorders. Specifically, patients with mood disorders were associated with COPD development $(\mathrm{RR}=1.59 ; 95 \%$ CI $1.07-2.36)$ compared to individuals without mood disorders. However, anxiety disorders were not associated with an increased development of COPD ( $R R=1.33$; 95\% CI $0.86-2.06$ ).

CONCLUSION: Mood, but not anxiety, disorders were independent risk factors for COPD development in individuals referred for an exercise stress test. Future studies could assess the potential impact of depression reduction interventions on the incidence of COPD.

Financial Support: KLL and SLB are supported by CIHR and FRQS salary awards.

\section{6 - CRC2015-042}

\section{INCREASED METS DURING EXERCISE STRESS TESTING IS} PREDICTIVE OF REDUCED RISK OF COPD DEVELOPMENT NJ Paine ${ }^{1,2}$, KL Lavoie ${ }^{1,3}$, A Moga ${ }^{1,4}$, G Moullec $^{1,5}$, C Laurin ${ }^{1}$, R Pelletier $^{1,6}$, A Arsenault ${ }^{1}$, SL Bacon ${ }^{1,2}$

${ }^{1}$ Montreal Behavioural Medicine Centre, Hopital du Sacre-Coeur de Montreal; ${ }^{2}$ Department of Exercise Science, Concordia University; ${ }^{3}$ Department of Psychology, University of Quebec at Montreal (UQAM); ${ }^{4}$ Department of Physical and Occupational Therapy, McGill University, Montreal; ${ }^{5}$ Department of Psychology, Universite du Quebec en Outaouais, Gatineau; ${ }^{6}$ Division of Internal Medicine, McGill University, Montreal, QC

RATIONALE: Chronic obstructive pulmonary disease (COPD) is a chronic respiratory disease, which is predicted to become the 3rd leading cause of death worldwide by 2030 . Increased cardiovascular fitness has been associated with reductions in the development of a number of chronic diseases and an improvement in outcomes in those with disease. This study evaluated the extent to which fitness (assessed using a standard exercise stress test) was predictive of subsequent COPD development.

METHODS: 1615 participants $(66.3 \%$ female, mean age $56.4 \pm 8.46$ years) completed a Bruce protocol exercise stress test as part of a cardiovascular disease assessment. Participants were excluded if they had experienced a cardiac event 4 weeks prior to testing or if they had either cancer or COPD. Peak metabolic equivalents (pMETs) was used as the measure of physical fitness. Post exercise stress testing, participants were followed over a mean period of $8.25 \pm 1.52$ years to record COPD development from provincial healthcare data. Cox Regression models investigated whether pMETs were predictive of subsequent COPD development, adjusting for sex, age, smoking status, CAD diagnosis, and hypertension medication.

RESULTS: The mean pMETs was $8.02 \pm 1.70$ (3.5 mL/kg/O $/ \mathrm{min})$. Increased pMETs was predictive of a reduced risk of COPD development, with every increase in one pMET lowering risk by $29.5 \%$ ( $\mathrm{HR}=0.705 ; 95 \%$ CI 0.612-0.812; $\mathrm{p}<0.001)$. Compared to the lowest quartile of pMETs, each quartile was associated with a decreased risk of developing COPD (Q2 $\mathrm{HR}=0.771$; $3 \mathrm{HR}=0.335$; $\mathrm{Q} 4 \mathrm{HR}=0.246$ ).

CONCLUSION: Higher pMETs (ie, greater fitness) during exercise stress testing was predictive of a reduced risk of COPD development, suggesting the use of an exercise stress test designed to diagnose cardiac conditions might also be effective in predicting COPD development. Future work should assess the potential benefits of increasing physical activity to help reduce the risk of developing COPD in the future.

Financial Support: Nicola J Paine is supported by an FRSQ postdoctoral fellowship. Salary support for Kim L Lavoie and Simon L Bacon is provided by CIHR and FRSQ.

\section{ILD / Lung Cancer / PVD}

$17 \cdot$ CRC2015-023

VALUE OF PREOPERATIVE COMPUTED TOMOGRAPHY IN ASSESSING THE COMPLETENESS OF LUNG FISSURES

C Bissonnette-Roy ${ }^{1}$, S Carignan ${ }^{2}$, G Rakovich ${ }^{1}$

${ }^{1}$ Department of Surgery; ${ }^{2}$ Department of Radiology, Hôpital

Maisonneuve-Rosemont, University of Montreal, Montreal, QC

INTRODUCTION: Obstacles to the widespread adoption of thoracoscopic lobectomy include technical difficulty and limited availability of operating room time. During major lung resections, incomplete (fused) lung fissures represent a significant technical challenge for the surgeon, especially when learning the technique. These may prolong operative times and increase the need for conversion to open thoracotomy. Predicting the completeness of the fissures preoperatively may help with optimizing case selection early in one's experience and help with OR scheduling.

METHODS: We included consecutive cases of major lung resections (both thoracoscopic and open) performed over an 8 month period by one of the authors (G.R.). Preoperative CT-scans were reviewed by 3 radiologists blinded to intraoperative findings. Fissures were rated on a five point likert scale (1- complete absence of fusion between lobes; 5 - completely fused lobes). FEV1 and BMI were assessed as a reflection of COPD severity and phenotype, respectively.

RESULTS: There were 28 patients for a total of 45 fissures. The correlation between the radiologists rating the preoperative CT-scan was $r=0.907$ $(\mathrm{p}<0.01), r=0.636(\mathrm{p}<0.01)$, and $\mathrm{r}=0.558(\mathrm{p}<0.01)$, respectively. The correlation between intraoperative findings and the findings on CT were $\mathrm{r}=0.715(\mathrm{p}<0.01), \mathrm{r}=0.634(\mathrm{p}<0.01)$, and $\mathrm{r}=0.562(\mathrm{p}<0.01)$, respectively. Radiologists were able to identify fissures considered technically "difficult" (rating 4.5) on preoperative CT with a likelihood [odds ratio] of 5.0 (2.589.72), 5.85 (2.82-12.05), and 4.0 (2.0-8.0) respectively. Age, sex, FEV1, and BMI did not correlate with intraoperative findings.

CONCLUSION: Our study found a significant correlation between findings on pre-operative CT scan and the the completeness (degree of fusion) of lung fissures found at operation, although radiologists tended to underestimate the degree of fusion somewhat compared to the surgeon. Pre-operative CT-scan was also likely to identify fissures considered technically difficult. Financial Support: None.

\section{8 - CRC2015-030}

\section{EFFECT OF BASELINE EMPHYSEMA ON REDUCTION IN} FVC DECLINE WITH NINTEDANIB IN THE INPULSIS TRIALS

G Cox ${ }^{1}$, V Cottin ${ }^{2}$, H Taniguchi ${ }^{3}$, L Richeldi ${ }^{4}$, HR Collard ${ }^{5}$, M Kaye ${ }^{6}$, DM Hansell', Z Bailes ${ }^{8}$, R Schlenker-Herceg9, G Raghu ${ }^{10}$

${ }^{1}$ St Joseph's Healthcare, Hamilton, ON; ${ }^{2}$ Louis Pradel Hospital, University of Lyon, France; ${ }^{3}$ Tosei General Hospital, Aichi, Japan; ${ }^{4}$ National Institute for Health Research Southampton Respiratory Biomedical Research Unit and Clinical and Experimental Sciences, University of Southampton, Southampton, United Kingdom; ${ }^{5}$ University of California San Francisco, San Francisco, CA, USA; ${ }^{6}$ Minnesota Lung Center, Ltd, Minneapolis, MN, USA; ${ }^{7}$ Royal Brompton and Harefield Hospital NHS Foundation Trust and National Heart and Lung Institute, Imperial College, London; ${ }^{8}$ Boehringer Ingelheim Ltd, Bracknell, United Kingdom; ${ }^{9}$ Boehringer Ingelheim Pharmaceuticals Inc, Ridgefield, CT; ${ }^{10}$ University of Washington, Seattle, WA, USA

BACKGROUND: The INPULSIS trials were two replicate randomized, placebo-controlled, 52-week Phase III trials that assessed the efficacy and safety of nintedanib $150 \mathrm{mg}$ twice daily in patients with IPF. In both trials, nintedanib slowed disease progression by significantly reducing the annual rate of decline in forced vital capacity (FVC), the primary endpoint, compared with placebo.

METHODS: A post-hoc subgroup analysis of the effect of nintedanib on the primary end-point in patients with or without emphysema at baseline, as assessed on qualitative central assessment of chest high-resolution computed tomography (HRCT) scans, was undertaken using pooled data from both trials. 
RESULTS: In total, 420 patients (nintedanib 254, placebo 166) had emphysema at baseline and 641 patients (nintedanib 384, placebo 257) did not. Baseline characteristics for patients with versus without emphysema were as follows: mean age 65.8 versus 67.4 years, $89.0 \%$ versus $72.9 \%$ were male, mean FVC \% predicted was $82.5 \%$ versus $77.7 \%$. There was no statistically significant treatment by subgroup interaction for the primary endpoint $(p=0.5199)$ : the adjusted annual rate of decline in FVC was $-105.1 \mathrm{~mL} /$ year with nintedanib and $-207.2 \mathrm{~mL} /$ year (difference: $102.0 \mathrm{~mL} /$ year [95\% CI 43.2, 106.9]) for patients with emphysema versus $-118.8 \mathrm{~mL} /$ year with nintedanib and $-234.2 \mathrm{~mL}$ /year with placebo (difference: $115.4 \mathrm{~mL} /$ year $[95 \%$ CI 73.8, 157.1]) for patients without emphysema at baseline.

CONCLUSION: A post-hoc subgroup analysis of pooled data from the INPULSIS trials demonstrated that nintedanib slowed disease progression by reducing the annual rate of FVC decline independent of the presence of emphysema at baseline.

Financial Support: Boehringer Ingelheim. Previously presented at ICLAF 2014 in Mont Tremblant, Quebec.

\section{9 - CRC2015-025}

\section{LEARNING CURVE DURING THE ADOPTION OF THORACOSCOPIC PULMONARY LOBECTOMY}

\section{S Facchino, G Rakovich}

Division of Thoracic Surgery, Hôpital Maisonneuve-Rosemont, University of Montreal, Montreal, QC

INTRODUCTION: Advanced thoracoscopic techniques have allowed to perform pulmonary lobectomy with decreased morbidity and mortality compared to open thoracotomy. However, these techniques may be difficult to learn and adoption has not been universal. Our objective was to evaluate our learning curve for thoracoscopic lobectomy since introducing the technique into our practice. We hypothesized that increased expertise would lead to decreased operative times, improved lymph node sampling, and decreased intra and postoperative complications.

METHODS: All cases of thoracoscopic lobectomy performed by a single surgeon between 2009 and 2014 were reviewed. Data were collected on operative indications, operative times, conversion rates, operative blood loss, nodal dissection, and postoperative complications.

RESULTS: Fifty-two cases were available for review. There were 27 males and 25 females. Mean age was $64 \pm 11.0$ years. Mean $\mathrm{FEV}_{1}$ was $2.17 \pm 0.66 \mathrm{~L}$. Most lobectomies were performed for lung cancer (80,8\%; adenocarcinoma $69 \%$; stage I $85.7 \%$ ). A curve of operative times suggested a consistent decrease after case 28 . We therefore compared the first 28 cases with the following 24 cases. There was no significant difference in age, sex, $\mathrm{FEV}_{1}$, tumor histology, or stage. Mean operative times were $259 \pm 59.8$ vs $188 \pm 59.0 \mathrm{~min}(\mathrm{p}<0.001)$. Conversion rates were $21.4 \%$ vs $12.5 \%$ respectively $(\mathrm{p}=0.09)$. Mean number of mediastinal lymph node stations sampled was $1.5 \pm 0.71$ vs $2.0 \pm 0.86(\mathrm{p}<0.05)$. Operative blood loss was $293.8 \pm 210.56$ vs $279.2 \pm 229.33 \mathrm{~mL}$ (n.s.). There was no significant difference in duration of postoperative chest tube drainage ( $6.0 \pm 2.84$ vs $6.6 \pm 5.16$ days $)$, major complication rates $(7.1 \%$ vs $8.3 \%)$, or hospital stay $(8.0 \pm 3.47$ vs $7.8 \pm 4.57$ days). CONCLUSIONS: After introducing thoracoscopic lobectomy into our practice, operative times significantly decreased after cases 25-30. This coincided with a strong trend toward decreased conversion rates to open thoracotomy and improved lymph node sampling. Morbidity was similar early on and later in our experience.

Financial Support: None.

\section{0 - CRC2015-031 \\ EFFECT OF BASELINE FVC ON DECLINE IN LUNG FUNCTION WITH NINTEDANIB: RESULTS FROM THE INPULSIS ${ }^{\text {TM }}$ TRIALS}

C Fell $^{1}$, U Costabel ${ }^{2}$, Y Inoue ${ }^{3}$, L Richeldi ${ }^{4}$, HR Collard ${ }^{5}$, S Stowasser 6 , I Tschoepe ${ }^{7}$, A Azuma ${ }^{8}$

${ }^{1}$ South Health Campus Hospital, Calgary, AB; ${ }^{2}$ Ruhrlandklinik, University Hospital, University of Duisburg-Essen, Essen, Germany; ${ }^{3}$ National Hospital Organization Kinki-Chuo Chest Medical Center, Osaka, Japan; ${ }^{4}$ University of Southampton, Southampton, United Kingdom; ${ }^{5}$ University of California San Francisco, San Francisco, CA, USA; ${ }^{6}$ Boehringer Ingelheim Pharma GmbH \& Co KG, Ingelheim am Rhein, Germany; ${ }^{7}$ Boehringer Ingelheim France SAS, Reims, France; ${ }^{8}$ Nippon Medical School, Tokyo, Japan

BACKGROUND: Nintedanib, an intracellular inhibitor of tyrosine kinases, is in development for the treatment of idiopathic pulmonary fibrosis (IPF). The INPULSIS ${ }^{\mathrm{TM}}$ trials were two replicate randomized, doubleblind, placebo-controlled, 52-week Phase III trials that assessed the efficacy and safety of nintedanib $150 \mathrm{mg}$ twice daily in patients with IPF. The primary endpoint was the annual rate of decline in forced vital capacity (FVC), which was significantly reduced in the nintedanib group compared with placebo in both trials.

AIM: To assess the impact of baseline FVC on the effect of nintedanib on rate of decline in FVC.

METHODS: A pre-specified subgroup analysis of patients with baseline FVC $>70 \%$ versus $\leq 70 \%$ of predicted value was undertaken using pooled data from both trials.

RESULTS: 700 patients (nintedanib 431, placebo 269) had baseline FVC $>70 \%$ predicted and 361 patients (nintedanib 207, placebo 154) had baseline FVC $\leq 70 \%$ predicted. For patients with a baseline FVC $>70 \%$ predicted, mean age was 67.4 years, $76.9 \%$ were male, $55.7 \%$ were White and mean carbon monoxide diffusion capacity (DLCO) was $4.0 \mathrm{mmol} / \mathrm{min} / \mathrm{kPa}$. For patients with a baseline $\mathrm{FVC} \leq 70 \%$ predicted, mean age was 65.5 years, $83.9 \%$ were male, $60.4 \%$ were White and mean DLCO was $3.6 \mathrm{mmol} / \mathrm{min} / \mathrm{kPa}$. There was no significant treatment by subgroup interaction: the difference in adjusted annual rate of decline in FVC between the nintedanib and placebo groups was comparable in both subgroups.

CONCLUSION: A subgroup analysis of pooled data from the INPULSIS $^{\text {TM }}$ trials showed that nintedanib $150 \mathrm{mg}$ twice daily slowed the decline in lung function in patients with IPF, independent of severity of lung function impairment at baseline.

Financial Support: Boehringer Ingelheim. Previously presented at ERS 2014 in Munich, Germany.

\section{1 - CRC2015-057 \\ COMPARATIVE STUDIES OF ASBESTOS PHAGOCYTOSIS IN MURINE AND HUMAN MACROPHAGES}

IS Khan, A Brahmendra, A Prashar, MR Terebiznik

Department of Biological Sciences; Department of Cell \& Systems Biology, University of Toronto, Toronto, ON

RATIONALE: Asbestos is a group of fibrous silicate minerals that causes pulmonary diseases, including malignant mesothelioma and bronchogenic carcinoma. According to fibre toxicology, the pathogenicity of asbestos and other respirable fibres is due to the frustrated phagocytosis of fibres exceeding $15 \mu \mathrm{m}$ in length, which results in the stimulation of cells to release inflammatory mediators and contributes to fibrosis. The cellular mechanisms that cause frustrated phagocytosis are unknown, largely due to a lack of techniques to study the internalization of these fibres by macrophages. Investigating these mechanisms is critical given the continued use of asbestos and other fibres worldwide, and the increasing use of newlydeveloped nanofibres, which are proposed to elicit similar responses. We developed immunofluorescence and indirect opsonization methods that allowed us to investigate the phagocytosis of asbestos fibres using confocal microscopy in cultured murine and human macrophages.

RESULTS: Our findings indicate key differences in the phagosomal uptake and maturation of asbestos fibres between these cell types. RAW 264.7 murine macrophages can internalize long asbestos fibres, albeit through a process 
which deviates from the canonical phagocytic pathway. However, internalization in U937 human macrophages is arrested at the cup stage. Interestingly, indirect opsonization of fibres with $\operatorname{IgG}$, which directs uptake via Fcg receptors, restores phagocytosis, likely due to the engagement of more receptors. Regardless of the uptake process, phagosomes containing asbestos fibres in both cell types fail to acidify, suggesting a deviation from the canonical phagosomal maturation pathway, possibly contributing to pathogenicity.

CONCLUSIONS: Altogether, our results suggest that along with fibre length, a deficiency in receptors for asbestos recognition could contribute to an anomalous phagocytic uptake process. Our techniques allow us to follow the phagocytosis of asbestos fibres and study the contribution of frustrated phagocytosis towards disease, as well as identify other points to be explored to explain the toxicity of these fibres.

Financial Support: NSERC Discovery Grants Program.

\section{2 - CRC2015-016}

UTILITY OF THE TRANS-ESOPHAGEAL CONTRAST ECHOCARDIOGRAM AS AN ADDITIONAL SCREENING TOOL FOR CARDIO-PULMONARY SHUNT ASSESSMENTS IN HEREDITARY HEMORRHAGIC TELANGIECTASIA

H Mann ${ }^{1}$, M Shanks ${ }^{2}$, J Choy ${ }^{2}$, U Geisthoff ${ }^{3}$, H-W Angened ${ }^{4}$, S Weise $^{4}$, D Vethanayagam ${ }^{2}$

${ }^{1}$ Faculty of Science; ${ }^{2}$ Department of Medicine, Faculty of Medicine, University of Alberta, Edmonton, $\mathrm{AB} ;{ }^{3}$ Department of $\mathrm{ORL}$;

${ }^{4}$ Department of Internal Medicine, Germany HHT Center, Hospitals of the City of Cologne, Germany

INTRODUCTION: Hereditary Hemorrhagic Telangiectasia (HHT) is an autosomal dominant disorder characterized by abnormal vascular maturation, resulting in the development muco-cutaneous telangiectasias and arterio-venous malformations (AVMs). Pulmonary AVMs (PAVMs), seen in $35-40 \%$ of HHT patients, can have significant clinical consequences due to the right-to-left shunt created.

RATIONALE: Transthoracic contrast echocardiography (TTCE) paired with chest radiography has been utilized at HHT Centers to optimize detection of shunts. However, TTCE cannot always delineate the nature and location of the noted shunt; the utility of more invasive screening with trans-esophageal contrast echocardiogram (TECE) has been explored.

METHODS: We sought to assess the proportion of HHT patients seen at the Edmonton and Germany HHT Centers where TECE was performed following TTCE for better delineation of the identity of a shunt. Inclusion criteria included either possible or definite HHT subjects who had undergone TTCE and/or TECE screening.

RESULTS: 257 subjects who had undergone TTCE and/or TECE screening were studied. In 92 of the 141 (54.9\%) cases where both TTCE and CT were performed, the results of the screenings conflicted in regards to the presence of a shunt. Of the 43 subjects (out of 45 ) positive for both TTCE and TECE, $11(26.2 \%)$ saw a reclassification in the shunt type and 1 subject $(2.4 \%)$ saw the discovery of a new shunt altogether.

CONCLUSIONS: The results of this study show potential benefits for adapting TECE to the normal screening protocol for a limited subset of HHT patients with unclear shunt identities. Clarity in intrathoracic shunt location can have important implications for diagnosis and management of HHT (possible vs. definite HHT). This may secondarily positively impact overall health care utilization and cost to the health care system if used in HHT Centers.

Financial Support: None.
$23 \cdot$ CRC2015-060

QUALITY OF LIFE ACCORDING TO CANCER TYPE IN PATIENTS WITH MALIGNANT PLEURAL EFFUSION TREATED WITH INDWELLING PLEURAL CATHETER OR TALC PLEURODESIS

JAP Olfert ${ }^{1}$, ED Penz ${ }^{1}$, EK Mishra ${ }^{2}$, HE Davies ${ }^{3}$, BJ Manns ${ }^{4}$, RF Miller ${ }^{5}$, NM Rahman ${ }^{2}$

${ }^{1}$ Department of Medicine, Division of Respirology, University of Saskatchewan, Saskatoon, SK; ${ }^{2}$ Oxford Respiratory Trials Unit, University of Oxford, Oxford; ${ }^{3}$ University Hospital of Wales, Cardiff, Wales, United Kingdom; ${ }^{4}$ Departments of Medicine and Community Health Sciences, University of Calgary, Calgary, AB; ${ }^{5}$ Research Department of Infection and Population Health, University College London, London, United Kingdom

RATIONALE: The Second Therapeutic Intervention in Malignant Effusion Trial (TIME2) ${ }^{1}$, compared indwelling pleural catheter (IPC) with talc pleurodesis (Talc) for treatment of malignant pleural effusion. Various clinical and economic outcomes have been published previously. ${ }^{1,2}$ Quality of life according to cancer type has yet to be described.

METHODS: 106 patients at 7 centers across the UK were randomized to either indwelling pleural catheter or Talc and followed for one year or until death. Dyspnea and chest pain were assessed using a $100-\mathrm{mm}$ line visual analog scale. Quality of life was assessed by EORTC-QLQ 30 and EQ-5D questionnaires. Quality-adjusted life-years (QALYs) gained were determined by area under the curve methodology using utility weights obtained from EQ-5D questionnaire. Analysis was performed according to cancer type and treatment modality.

RESULTS: Baseline utility scores for IPC and Talc groups by cancer type were: breast $(0.637$ versus 0.634$)$, lung $(0.553$ versus 0.553$)$, mesothelioma (0.634 versus 0.816$)$, and other ( 0.566 versus 0.588$)$. Mean QALY observed during the trial by cancer type was: breast (0.407), lung (0.252), mesothelioma (0.573) and other (0.298). The difference in mean QALY between IPC and Talc was not significant among different cancer types.

CONCLUSION: There was no significant difference in QALYs gained with IPC compared to Talc when stratified by cancer type. Mesothelioma was associated with the highest QALYs; however, baseline utility scores were highest in this group. Power to detect a difference in QALYs by cancer type may have been limited by small sample size.

Financial Support: The TIME2 trial was supported with an unrestricted education grant from the British Lung Foundation and the Robert Luff Foundation, London, England. The University of Oxford sponsored the TIME2 trial. The IPCs and drainage bottles were provided by Rocket Medical, Washington, England. An Alberta Innovates Health Solutions Clinician Fellowship award supported Dr. Penz during her involvement in the analysis and preparation of the manuscript. Dr. Manns is supported by Alberta Innovates - Health Solutions salary award and by an alternative funding plan from the Government of Alberta and Universities of Alberta and Calgary. No additional funding was provided for this study.

Conflicts of Interest: Dr Miller reported receiving support for lectures on HIV infection from Merck and Gilead. Dr Rahman reported that he acts as a consultant to Rocket Medical for device development. No other conflicts of interest were reported.

\section{4 - CRC2015-020}

\section{TRANSBRONCHIAL BIOPSIES IN LUNG CANCER:} RETROSPECTIVE REVIEW OF 116 PATIENTS

PS Zhu, CD Poirier, M Gagnon, T Vandemoortele

Department of Respirology, CHUM Hôpital Notre-Dame, Université de Montréal, Montreal, QC

RATIONALE: Bronchoscopy with transbronchial biopsy (TBB) is an interesting tool in the investigation of lung cancer. We aimed to describe the yield and safety of TBB in the evaluation of pulmonary malignancy. METHODS: We retrospectively reviewed the data of 116 TBB performed to assess lung lesions executed between January 2013 and December 2013 at a tertiary center. We evaluated these procedures in terms of diagnostic yield for neoplasia and complications. 
RESULTS: The mean age of the patients was 66 years old (range 26-88), with 55 male $(48.9 \%)$. The mean number of biopsies was $4.28( \pm 1.46)$. Diagnostic yield from TBB alone for lung cancer was 37.9\% (44/116), while when combined with other sampling procedures (such as bronchial biopsy, bronchoalveolar lavage or brush), it improved to $43.1 \%$ (50/116). When endobronchial ultrasound-transbronchial needle aspiration (EBUSTBNA) was also performed, diagnostic yield further increased to $58.6 \%$ (68/116). A higher number of biopsies improved the diagnostic yield ( $72.7 \%$ with $>5$ biopsies vs $36.7 \%$ with $3-5$ biopsies vs $0 \%$ with $1-2$ biopsies; $\mathrm{p}=0.015$ ). Diagnostic yield was higher when lesions measured $\geq 30 \mathrm{~mm}$ $(46.3 \%$; $31 / 67)$ compared with nodules $<30 \mathrm{~mm}$ in diameter $(25.6 \%$; $10 / 39)$ [ $p=0.041]$. Adjuncts such as radial EBUS (8/116), electromagnetic navigation (19/116), fluoroscopy (17/116) and cryoprobe (4/116) were used in 29 TBB (25\%), with no significant effect on performance $(\mathrm{p}=0.659)$. Only one patient suffered from a small pneumothorax $(0.9 \%)$ that did not require chest drainage. Number of biopsies did not influence the risk of complications.

CONCLUSIONS: Efficacy of TBB for the diagnosis of lung cancer is optimized when performed in conjunction with EBUS-TBNA, $>5$ biopsies and lesions $\geq 30 \mathrm{~mm}$. TBB appears to be a relatively safe procedure, with no significant rise in risk of complications with higher number of biopsies.

\section{$25 \cdot$ CRC2015-004}

\section{THE PATIENT WHO COULDN'T QUITE CATCH HER} BREATH: INTERSTITIAL LUNG DISEASE COMPLICATED BY HEPATOPULMONARY SYNDROME

\section{N Sitzer ${ }^{1}$, R Mathew ${ }^{1}$, J Gelberg ${ }^{1,2}$}

\section{${ }^{1}$ Department of Medicine; ${ }^{2}$ Division of Respirology, McMaster} University, Hamilton, ON

RATIONALE: Hepatopulmonary syndrome (HPS) is a triad of liver disease, impaired oxygenation and intrapulmonary vascular dilatations. While dyspnea is the predominant presenting symptom, platypnea and orthodeoxia are highly suggestive of HPS in the setting of chronic liver disease. A delay in diagnosis is common as dyspnea in cirrhotic patients is often attributed to ascites, anemia, muscle wasting or portopulmonary hypertension. The clinical picture is further complicated in patients with underlying lung pathology and baseline dyspnea.

METHODS: A 56-year-old female with rapidly progressive idiopathic pulmonary fibrosis and alcoholic liver disease presented to the Emergency Department with worsening dyspnea and increased oxygen requirements. She was empirically treated for a respiratory infection with ceftazadime, levofloxacin and oseltamivir. CT chest revealed worsening pulmonary fibrosis, but no etiology for her acute deterioration. While in hospital she was noted to have orthodeoxia and platypnea suggestive of HPS. Echocardiogram with agitated saline contrast revealed a patent foramen ovale with bidirectional shunting and large inflow of contrast from the pulmonary veins, worse in the upright position compared to the supine position. These findings were consistent with a large intrapulmonary shunt and a preliminary diagnosis of HPS. She is currently under review by the transplant board in Toronto for a combined liver and lung transplant.

CONCLUSION: In patients with interstitial lung disease, worsening dyspnea is often attributed to infection, congestive heart failure, pulmonary embolus or progression of underlying fibrosis. Our case highlights the importance of considering a broad range of differential diagnoses in patients presenting with progressive dyspnea, especially in the setting of in underlying chronic liver disease. Early recognition of HPS can lead to referral for definitive treatment with liver transplant.

\section{6 - CRC2015-024}

A MULTI-SPECIALTY THORACIC ONCOLOGY CLINIC FOR INDIVIDUALIZING THE CARE OF HIGH-RISK PATIENTS

C-A Vallée ${ }^{1}$, A Bujold ${ }^{2}$, S Carignan ${ }^{3}$, G Rakovich ${ }^{1}$

${ }^{1}$ Department of Surgery; ${ }^{2}$ Department of Radiation Oncology;

${ }^{3}$ Department of Radiology, Hôpital Maisonneuve-Rosemont,

University of Montreal, Montreal, QC

RATIONALE: There are several options available for treating early stage lung cancer. Although lobectomy remains the standard of care, sub-lobar resection, stereotactic radiotherapy and radio-frequency ablation may be appropriate in high risk patients. Direct evidence comparing these methods is lacking and thus therapeutic decisions are often deferred to an institutional "multidisciplinary tumor committee". We hypothesized that a multispecialty thoracic oncology clinic could streamline patient evaluation as well as improve outcomes by fine tuning therapeutic decisions based on specific patient and tumour characteristics.

METHODS: The proposed clinic was held jointly by a thoracic surgeon, radiation oncologist and interventional radiologist, beginning in March 2013. After 18 months, data were reviewed.

RESULTS: A total of 36 patients were evaluated. Mean age was $69 \pm 11.7$ years. Mean $\mathrm{FEV}_{1}$ was $1.83 \pm 0.59 \mathrm{~L}$. 14 patients had been treated for at least one distinct lung cancer in the past. 24 patients now had new single lesions, while 7 patients had multiple synchronous lesions. All had early stage tumors. An additional 5 patients had pulmonary metastases. After evaluation, 26 patients were referred for non-operative treatment: 16 because of co-morbidities and 10 because of patient preference. Eighteen patients had radiotherapy and 8 had ablation. Three patients had surgical resection, and 1 had combined resection and radiotherapy for synchronous tumors. Six patients with suspicious lesions were observed. There were 2 cancer related deaths and 2 distant metastasic recurrences during the study period. There were no treatment related adverse events.

CONCLUSION: The main indications for referral were a complex oncologic history and multiple tumors. Our approach facilitates individualized care and active participation of patients in decision-making. It also offers the potential for avoiding multiple specialty referrals and delays. Although follow-up is limited, patient outcomes were satisfactory and morbidity was minimal. Referral criteria and treatment options still need to be further refined. Financial Support: None.

\section{Knowledge Translation}

\section{7 - CRC2015-049}

\section{COLLABORATIVE CARE IN OSA: A NEW PARADIGM}

ME Fenton $^{1}$, SA Stewart ${ }^{2}$, RP Skomro' ${ }^{1}$, JA Gjevre ${ }^{1}$, S McCrae $^{3}$ ${ }^{1}$ Division of Respirology, Critical Care and Sleep Medicine; ${ }^{2}$ Department of Medicine, University of Saskatchewan, Saskatoon; ${ }^{3}$ Sleep Disorders Centre, Saskatoon Health Region, SK

BACKGROUND: Obstructive sleep apnea (OSA) is a prevalent disorder with a quarter of the Canadian population at high risk, that has traditionally been investigated and managed by specialists. There are two bottlenecks in the path of a patient seeking investigation and treatment of OSA - a specialist waitlist and sleep laboratory waitlist. Our centre has been providing level 3 testing since 2006, reducing the sleep-lab waitlist. To address the specialist bottleneck, we developed a new care-pathway providing testing and treatment directly from primary care. This model investigates the effect of this direct access (DA) program on patient wait-times and OSA diagnosis rates.

METHODS: Patients with a high pretest probability of OSA without significant comorbidities were referred directly to level 3 testing at the Sleep Disorders Centre. After review of the data by a sleep specialist, patients with a positive study were sent for education and auto-CPAP titration to determine fixed pressure CPAP settings. Indeterminate and complex findings were sent for polysomnography. We surveyed wait-times in 5 sleep specialist clinics in the Saskatoon Health Region (SHR) for comparison.

RESULTS: A total of 647 patients ( $53 \%$ male) were referred for direct testing. The median time from family physician referral to level III testing was 30 days for direct access (DA) patients, compared to 265 days for those seen by specialists $(\mathrm{HR}=4.8, \mathrm{P}<0.0001) .71 .6 \%$ of DA patients were diagnosed with OSA, compared to $79.2 \%$ in the specialist group ( $8.6 \%$ difference, $\mathrm{P}<0.0001)$.

DISCUSSION: Using this DA model, the time to diagnosis for patients with OSA was significantly decreased. The diagnostic rate of $71 \%$ by level 3 for DA is below the specialist arm but is acceptable. This study demonstrates the potential for direct to level III referral to significantly reduce wait times and improve time to treatment. 


\section{8 - CRC2015-040}

A MULTI-STAKEHOLDER COLLABORATION TO IMPROVE OUTCOMES IN PATIENTS WITH CHRONIC OBSTRUCTIVE PULMONARY DISEASE (COPD) IN ONTARIO: VALUE DEMONSTRATING INITIATIVE (VDI) ON COPD

C Madeley ${ }^{1}$, A Barlett ${ }^{2}$, D Brooks ${ }^{3}$, J Cafazzo ${ }^{4}$, C Faulds $^{5}$, A Gershon $^{6}$, J Glennie ${ }^{7}$, M Hillmer ${ }^{8}$, C Hay ${ }^{9}$, A Hayes ${ }^{10}$, A Kaplan ${ }^{11}$, L LeBlanc $^{12}, \mathrm{C}$ Licskai $^{13}$, M Lundie $^{14}$, K McIntyre ${ }^{15}$, J Plaxton ${ }^{16}$, J Pringle ${ }^{17}$, R Maleki-Yazdi ${ }^{18}$

${ }^{1}$ Ontario Lung Association; ${ }^{2}$ Firestone Institute for Respiratory Health, McMaster University, Hamilton; ${ }^{3}$ West Park Hospital, University of Toronto; ${ }^{4}$ University of Toronto, Toronto; ${ }^{5}$ London Family Health Team, Ontario College of Family Physicians, London; ${ }^{6}$ Sunnybrook Hospital, Institute for Clinical Evaluative Sciences; ${ }^{7}$ Pharmacist/ Private Consultant; ${ }^{8,9,10}$ Ontario Ministry of Health and Long-Term Care; ${ }^{11}$ Family Physician Airways Group of Canada; ${ }^{12}$ Ontario Lung Association; ${ }^{13}$ University of Western Ontario, St Joseph's Health Care, London; ${ }^{14}$ Pfizer; ${ }^{15}$ St Michael's Hospital; ${ }^{16,17}$ Ontario Ministry of Health and Long-Term Care; ${ }^{18}$ Women's College Hospital, University of Toronto, Toronto, ON

RATIONALE: COPD affects $12 \%$ of Ontarians and prevalence is increasing. COPD patients are among the high health care users. In order to improve their quality of life and increase the effectiveness of the health care system, an innovative collaboration between the Ministry of Health and Long-Term Care, the Ontario Lung Association, and Canada's ResearchBased Pharmaceutical Companies (Rx\&D) began in 2013. They worked together to translate existing knowledge and evidence into practice.

METHODS: An expert panel comprised of representatives from the collaborating organizations, respirologists, family physicians, pharmacists, respiratory therapists, researchers, and a patient representative provided evidence-based advice on the design, implementation, and evaluation of integrated multidisciplinary COPD care for patients at high risk of hospitalization. With the support of a secretariat based at the Ministry of Health and Long-Term Care, the Panel reviewed evidence and leading practices, and leveraged the recommendations of the Ontario Health Technology Advisory Committee (OHTAC) and Health Quality Ontario (HQO) to provide advice on:

Intervention design (eg, eligibility criteria, approaches to care coordination) Implementation considerations (e.g., care delivery, training)

Monitoring and evaluation (e.g., approaches to evaluating implementation, maintenance of intervention).

RESULTS: The Expert Panel designed a patient care pathway that is intended to: Improve patient level outcomes

Reduce healthcare utilization and costs (eg, hospital admissions, mean annual cost) Increase the number of patients reached with multidisciplinary COPD careIncrease patient adherence to, and healthcare provider uptake of, evidence based guidelines. The pathway was endorsed by all panel members in February 2014.

CONCLUSION: The VDI on COPD is being implemented in three regions in Ontario. A Clinical and Scientific Leadership Panel that includes members of the Expert Panel will monitor the integrity, safety, and ethics of the care pathway through implementation. An independent evaluator has been selected to work with the sites to analyze implementation and outcomes.

Financial Support: Canada's Research Based Pharmaceutical Companies $(R x \& D)$ ( provides funding support for implementation and evaluation), Ontario Lung Association and the Government of Ontario.

\section{9 • CRC2015-005 \\ PAST, PRESENT AND THE FUTURE OF RESPIRATORY RESEARCH: A SURVEY OF CANADIAN ALLIED HEALTH PROFESSIONALS}

M Nonoyama ${ }^{1}, \underline{\text { S Mathur }}^{2}$, R Herbert $^{3}$, H Jenkins ${ }^{4}$, M Lobchuk $^{5}$, M McEvoy ${ }^{6}$

${ }^{1}$ Faculty of Health Sciences, University of Ontario Institute of Technology, Oshawa; ${ }^{2}$ Department of Physical Therapy, University of Toronto, Toronto, ON; ${ }^{3}$ School of Nursing, University of Prince Edward Island, Charlottetown, $\mathrm{PEl} ;{ }^{4} \mathrm{Manitoba}$ Institute of Child Health; ${ }^{5}$ Faculty of Health Sciences, College of Nursing, University of Manitoba, Winnipeg, MN; ${ }^{6}$ Canadian Lung Association, Ottawa, ON RATIONALE: The Canadian Respiratory Health Professionals (CRHP) is the multidisciplinary allied health professional group of the Canadian Lung Association. Although the CRHP has a growing number of highly qualified researchers, the landscape of allied health professional respiratory research in Canada has not been described. The objectives of this study were to: describe the level of respiratory research engagement; identify barriers and facilitators to research engagement; describe the experience and interest in developing research skills; and identify priority areas of future respiratory research among allied health professionals.

METHODS: An online survey of CRHP members was used to collect demographic data; barriers and facilitators to conducting research; and future directions in respiratory research, research funding and mentorship. Experience with and interest in upskilling research skills was also evaluated. RESULTS: One hundred and nineteen surveys were completed (22\% response rate) of which 69 respondents (58\%) were engaged in respiratory research. Reasons for not being involved in respiratory research were lack of mentorship, support and funding. Top research areas were chronic obstructive pulmonary disease (74\%) and asthma (41\%). Top facilitators for research engagement were amount of funding (29\%) and mentorship (28\%). Respondents rated their experience in research skills as low but expressed high interest in improving their research skills.

CONCLUSIONS: We identified areas of development such as research skills, greater funding opportunities and mentorship to increase the research capacity of allied health professionals in respiratory health. Allied health researchers have an important role in contributing to the national respiratory research strategy to increase interdisciplinary engagement and build collaborative teams.

Financial Support: None.

\section{$30 \cdot$ CRC2015-037 \\ USE OF AN APP TO PROVIDE CLINICAL DECISION SUPPORT FOR COPD USING THE CTS GUIDELINES AT POINT OF CARE}

R Mehta $^{1}$, M Braganza ${ }^{2}$, A Ganesh ${ }^{3}$, S Fields ${ }^{4}$, R Leigh $^{5}$

1,2,3 Department of Medicine, Foothills Medical Centre;

4,5 Department of Respirology, University of Calgary, Calgary, AB

RATIONALE: The implementation of clinical guidelines in primary care is often limited by complexity, accessibility and inability to integrate within the clinical setting. Only $50 \%$ of patients in North America receive the recommended care as set out by COPD guidelines. Three main factors have been identified which limit physician adherence to guidelines: knowledge deficiency, attitude (lack of outcome expectancy, self-efficacy, motivation) and behavioral challenges (lack of time, reimbursement, organizational/resource factors). We have built a tool which incorporates the CTS COPD Guidelines into an Ipad/Iphone app which addresses some of these factors and can be used at the point of care.

METHODS: We are conducting a multistage study: Stage1: Design, Stage 2: Development and Stage 3 Validation of the COPD based on CTS guidelines. RESULTS: We have finished the first 2 stages of the study which involves design and development of a COPD app to deliver evidence based care. A demo of the app can be accessed at:

https://drive.google.com/file/d/OB7TXi_Qxc5YALVNkNUZtZUd3TEO/ view?usp=sharing

CONCLUSION: There are very studies on validating medical apps from design to implementation. We are now in the process of conducting a study 
to gather data on the effectiveness of the COPD app. Key data that will be collected will include: time taken to complete the assessment, usability of the app, and clinical decision concordance with the guidelines.

Financial Support: We have received financial support for the development of through grants/awards from the Ward of 21 Century, University of Calgary \& World Health Innovation Academy, University of Geneva, Switzerland.

\section{1 - CRC2015-055 \\ EFFECTS OF A MULTI-FACETED MENTORING INTERVENTION ON SPIROMETRY KNOWLEDGE, QUALITY AND USAGE IN PRIMARY CARE. THE PRIMARY CARE ASTHMA PROGRAM (PCAP) COLLABORATIVE CARE PILOT PROJECT (CCPP)}

D Moosa $^{1}$, I Tamari ${ }^{2}$, C Allen ${ }^{3}$, A MacPherson ${ }^{4}$, S Gupta ${ }^{5}$

${ }^{1}$ Ontario Lung Association; ${ }^{2}$ Stonegate Community Health Centre; ${ }^{3}$ Hamilton Firestone Institute, Hamilton; ${ }^{4}$ Southlake Regional Health Centre; ${ }^{5} \mathrm{Li}$ Ka Shing Knowledge Institute of St Michael's Hospital, Department of Medicine, University of Toronto, Toronto, ON

RATIONALE: Asthma is the third most common chronic disease in adults, affecting $8.1 \%$ of the Canadian population. Only $35 \%$ of patients with asthma report having had spirometry, and $46 \%$ of primary care physicians report using spirometry to monitor asthma. Regular use of spirometry in primary care has been shown to decrease over diagnosis and to improve medication adherence. We sought to design and evaluate a knowledge translation intervention to address the underuse and poor quality of spirometry in primary care. The intervention was designed on the basis of an extensive barriers and facilitators evaluation, and modelled on a peer mentorship program developed by the Ontario College of Family Physicians.

METHODS: This was a pre-and post-analysis, comparing outcomes during a 1-year intervention period to those in the year prior. The program established three mentor-mentee "pods," each including physician and allied health mentors and corresponding mentees, connected through various methods of communication. We recruited mentees from seven Ontario primary care asthma program sites representing rural, urban, remote and underserviced populations. Outcomes included: 1) knowledge of spirometry performance and interpretation (self-administered online test); 2) quality of spirometry (spirometry tracings evaluated with ATS/ERS standards); and 3) actual usage of spirometry in patients with established asthma (chart reviews of electronic medical records).

RESULTS: We recruited 11 mentors and 47 mentees. Spirometry knowledge scores increased significantly $[(21.4 \pm 3.1$ to $27.3 \pm 3.5 \quad(\mathrm{p}<0.01)]$. Spirometric acceptability and repeatability criteria were met by $59 / 191$ (30.9\%) spirometry tracings pre-intervention and 86/193 (44.6\%) postintervention [odds ratio $1.72(1.27,2.34)]$. Finally, spirometry was ordered in $75 / 512(14.6 \%)$ and $129 / 336(38.4 \%)$ of respiratory visits $(\mathrm{p}<0.01)$ pre and post-intervention, respectively.

CONCLUSION: A mentorship-based intervention involving both primary care physicians and allied health practitioners can enhance knowledge, technical competence, and actual use of spirometry in eclectic, real world primary care settings.

\section{$32 \cdot$ CRC2015-056}

\section{INNOVATIONS IN TREATING CHRONIC OBSTRUCTIVE PULMONARY DISEASE (COPD) EXACERBATIONS USING NEW TECHNOLOGY}

M Sedeno, P-Z Li, A Joubert, I Drouin, R Abimaroun, I Ouellet, D Beaucage, M Patel, J Bourbeau

Respiratory Epidemiology and Clinical Research Unit (RECRU), Montreal Chest Institute, McGill University Health Centre (MUHC), Montreal, QC

INTRODUCTION: We conducted a pilot study evaluating the feasibility and potential benefits of a novel approach of COPD self-management that includes an interactive phone assessment/reporting system (COPDTelesystem) in addition to a written action plan and a nurse case manager support to improve patients' adherence to prompt COPD treatment in those at risk for exacerbations.
METHODS: Prospective cohort of COPD patients (GOLD 2+) with $\geq 1$ exacerbations requiring antibiotic or prednisone in the past year. Patients received scheduled calls from the COPD-Telesystem at 2 weeks and months 1-6 to evaluate the presence of an exacerbation and remind them to follow their action plan; they could also call the COPDTelesystem to report changes or new respiratory symptoms. The case manager received an alarm in case of exacerbation and called back patients for follow-up. Outcomes evaluation by monthly phone interview for 12 months included patients' use of rescue bronchodilators, antibiotics and/or prednisone in response to exacerbation symptoms and use of healthcare resources.

RESULTS: Twenty-four COPD patients were recruited and 16 experienced exacerbations. A total of 39 exacerbations were recorded. Although 36 exacerbations presented increased shortness of breath, only 2 increased rescue bronchodilators, and 2 took prednisone. Antibiotics were used in 4 out of 26 exacerbations presenting changes in sputum. There were 14 severe exacerbations (requiring either a doctor or ER visit or hospitalization), and these lasted longer than non severe (21.9 versus 9.1 days).

CONCLUSIONS: To date, patients have not demonstrated adherence to the action plan directives in case of a COPD exacerbation. This calls for a more intensive follow-up from the nurse case manager to support the use of the COPD-Telesystem for reporting and the action plan.

Financial Support: Investigator-initiated study funded by GlaxoSmithKline.

\section{Pediatric Asthma and Lung Diseases}

\section{$33 \cdot$ CRC2015-046 SPONTANEOUS PNEUMOMEDIASTINUM IN A HEALTHY NEWBORN}

\section{$\underline{\text { S Bin-Hasan, R Amin }}$}

Division of Respiratory Medicine, Hospital for Sick Children; University of Toronto, Toronto, ON

BACKGROUND: Spontaneous pneumomediastinum (PM) is an uncommon phenomenon in healthy, term newborns as it is estimated to occur in $0.1 \%$ to $0.2 \%$ of all live births. The pathophysiology is related to over distension and rupture of alveoli, with the escaped air following the path of the least resistance towards the hilum and the mediastinum. From the literature, management of asymptomatic PM varies from conservative management to application of $100 \%$ oxygen with similar outcomes.

CLINICAL CASE DESCRIPTION: A female infant was born at term via spontaneous vaginal delivery to a healthy mother with unremarkable antenatal history. Mom was Group B Strep (GBS) positive and received appropriate antenatal antibiotics. Because of an elevated white cell count of 32.6, the infant was started on Ampicillin and Gentamicin. The antibiotics therapy were discontinued 48 hours later when the blood cultures were negative. On clinical examination, the heart sounds were decreased over the upper anterior chest. The oxygen saturations were $100 \%$ in room air, there was no tachypnea or respiratory distress. A chest radiograph demonstrated a cystic abnormality in the left hemithorax. The differential diagnosis included a cystic lesion communicating with the airways versus a loculated PM. Chest CT scan confirmed the diagnosis of a loculated PM. The baby was discharged home and at the one month follow up visit, the repeat chest radiograph showed complete resolution of the PM.

CONCLUSION: Unlike other air-leak syndromes in the neonatal population, spontaneous PM is much less common especially in the absence of a barotrauma. The clinical assessment is very important to identify the subtle clues as presented in the case, as well as, a proper radiological assessment to confirm the diagnosis.

Following the patient clinically is essential to confirm the diagnosis as PM will resolve spontaneously without additional sequelae.

Financial Support: None. 


\section{4 - CRC2015-035}

1-YEAR EFFICACY AND SAFETY STUDY OF TIOTROPIUM RESPIMAT ADD-ON TO ICS IN ADOLESCENT PATIENTS WITH SYMPTOMATIC ASTHMA

M-A Caron ${ }^{1}$ (presenting on behalf of E Hamelmann ${ }^{2}$ ), A Boner ${ }^{3}$,

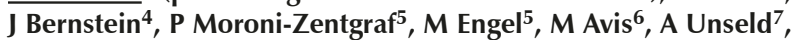
$M$ Vandewalker ${ }^{8}$

${ }^{1}$ Medical Affairs, Boehringer Ingelheim (Canada) Ltd, Burlington, ON; ${ }^{2}$ Department of Child and Adolescent Medicine, St Josef Hospital, Bochum, Germany; ${ }^{3}$ Pediatric Department, University of Verona, Verona, Italy; ${ }^{4}$ Department of Internal Medicine, University of Cincinnati Medical Sciences Building, Cincinnati, OH, USA; ${ }^{5} \mathrm{TA}$ Respiratory Diseases, Boehringer Ingelheim Pharma GmbH \& Co. KG, Ingelheim am Rhein, Germany; ${ }^{6}$ Trial Clinical Monitor, Boehringer Ingelheim bv, Alkmaar, Netherlands; ${ }^{7}$ Global Biometrics and Clinical Applications, Boehringer Ingelheim Pharma GmbH \& Co KG, Biberach an der Riss, Germany; ${ }^{8}$ Clinical Research of the Ozarks, Columbia, MO, USA

BACKGROUND: Tiotropium Respimat (tioR) add-on to ICS therapy improves lung function in adult patients. Here we examine the efficacy and safety of tioR in adolescents.

METHODS: 48-wk Phase III, randomised, double-blind, placebocontrolled, parallel-group trial (NCT01257230) in asthmatic adolescents (12-17 yrs). Inclusion criteria: $=3$-month asthma history; pre-bronchodilator FEV1 $=60 \%$ and $=90 \%$ of predicted; screening ACQ-7 $=1.5$. Patients were randomised to once-daily tioR $5 \mu \mathrm{g}$, tioR $2.5 \mu \mathrm{g}$ or placebo Respimat (pboR) add-on to ICS (12-14 yrs: 200-400 $\mu$ g; >14 yrs: 400-800 $\mu$ g budesonide or equivalent). Primary end point at wk 24: peak $\mathrm{FEV}_{1}(0-3 \mathrm{~h})$. Additional end points: trough FEV1 and PEFam/pm (wks 24 and 48), and AE data.

RESULTS: 397 patients treated. Mean age: 14.3 yrs (range 11-17 yrs); $65 \%$ male; mean $\mathrm{FEV}_{1} \%$ predicted at baseline: 82.8. TioR $5 \mu \mathrm{g}$ significantly improved all end points vs pboR at 24 and 48 wks; tioR $2.5 \mu \mathrm{g}$ significantly improved some end points, eg peak $\mathrm{FEV}_{1}(0-3 \mathrm{~h})$ at 24 and 48 wks and trough $\mathrm{FEV}_{1}$ at 48 wks. AEs were comparable across all treatment groups; a small number of drug-related AEs (tioR $5 \mu \mathrm{g}=4$, tioR 2.5 $\mu \mathrm{g}=1$, pboR=1) and no fatal AEs were reported.

CONCLUSION: Tiotropium Respimat add-on to ICS significantly improves lung function, has a safety profile comparable with placebo and is well tolerated in adolescent patients with symptomatic asthma.

Financial Support: Boehringer Ingelheim. Previously presented at ERS 2014 in Munich, Germany.

35 - CRC2015-058

THE INFLUENCE OF SOCIOECONOMIC INEQUITY ON THE LONG-TERM HEALTHCARE COSTS OF ASTHMA UNDER UNIVERSAL HEALTH INSURANCE

W Chen ${ }^{1}$, LD Lynd ${ }^{1,2}$, JM FitzGerald ${ }^{3,4}$, M Sadatsafavi ${ }^{3,4}$

${ }^{1}$ Collaboration for Outcomes Research and Evaluation, Faculty of Pharmaceutical Sciences, University of British Columbia,

Vancouver; ${ }^{2}$ Centre for Health Evaluation and Outcome Sciences,

Providence Health; ${ }^{3}$ Division of Respiratory Medicine, Faculty of

Medicine; ${ }^{4}$ Institute for Heart and Lung Health, University of

British Columbia, Vancouver, BC

RATIONALE: In asthma low-socioeconomic status (SES) tends to contribute excess health-care burden, but its impact on asthma costs in a universal health-care system is unknown. This study examined the extent of SES-related disparities in the long-term direct medical costs of asthma and trends over time.

METHODS: Using BC's administrative data, between January 1997 and March 2013, asthma patients were identified using a validated case definition. Index date was defined as the first day after the first asthma diagnosis. Each asthmatic was matched to a non-asthmatic based on age and sex, the latter was assigned the same index date. Participants aged 18 to 45 years on the index date were included in the final analysis. SES was defined by median neighborhood household income quintile in the index year. Excess health-care costs were reported in 2013 Canadian dollars, including allcause inpatient episodes, outpatient visits and medications from the billing records. A survival-adjusted, multipart generalized linear model was used to model the 15-year healthcare costs, accounting for death and early withdrawal. The impact of SES was assessed in participants with and without asthma, adjusting for age, sex and the year of asthma onset. The excess costs of asthma were determined by contrasting the predicted costs of asthmatics and non-asthmatics.

RESULTS: The sample included 53,988 asthma cases and non-asthma controls, respectively (both groups: mean age 33 years, 61\% female). People in the lowest SES quintile were expected to incur $\$ 3,243$ more covariate-adjusted excess costs of asthma over 15 years compared with the highest quintile $(\$ 19,772$ vs. $\$ 16,529, \mathrm{p}<0.001)$. Overall, lower SES was associated with greater 15-year asthma costs than higher SES (trend test: $\mathrm{p}<0.001)$. The gap of SES-related disparities in asthma costs widened over time.

CONCLUSIONS: Lower SES at onset of asthma is associated with greater medical costs over the long term.

Financial Support: This work was supported by AllerGen National Center of Excellence as part of the project "Platform for Outcomes Research and Translation in Asthma and Allergy (PORTAL)".

Conflict of Interest: The authors declare no conflict of interests.

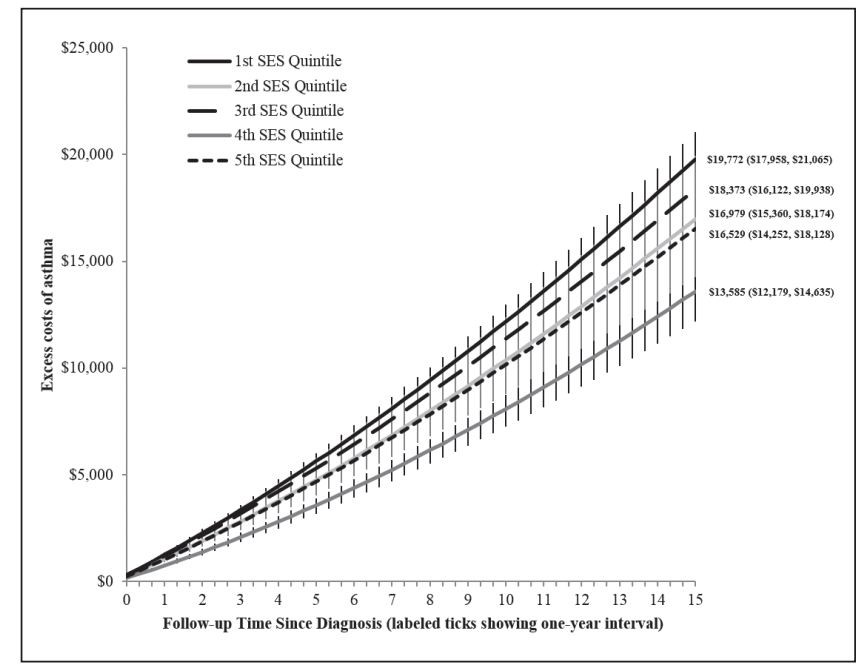

Figure 1) Covariate-adjusted excess costs of asthma per person by levels of SES, with $95 \%$ credible intervals.

\section{$36 \cdot$ CRC2015-009 \\ PRIMARY CILIARY DYSKINESIA AND NEONATAL RESPIRATORY DISTRESS}

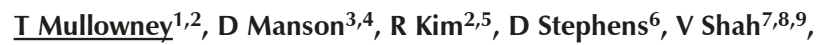
S Dell, 1,6,8,9

${ }^{1}$ Division of Respiratory Medicine, The Hospital for Sick Children; ${ }^{2}$ Department of Post Graduate Medical Education, University of Toronto; ${ }^{3}$ Department of Diagnostic Imaging, The Hospital for Sick Children; ${ }^{4}$ Medical Imaging, University of Toronto; ${ }^{5}$ Division of Clinical and Metabolic Genetics; ${ }^{6}$ Child Health Evaluative Sciences, The Hospital for Sick Children; ${ }^{7}$ Department of Paediatrics, Mount Sinai Hospital; ${ }^{8}$ Department of Paediatrics, University of Toronto; ${ }^{9}$ Institute of Health Policy, Management and Evaluation, University of Toronto, Toronto, ON

ABSTRACT NOT PUBLISHED AT AUTHORS' REQUEST 


\section{$37 \cdot$ CRC2015-010}

AUDIT OF INFLUENZA VACCINATION IN THE REGIONAL PAEDIATRIC ASTHMA CLINIC (RPAC) WITH COMPARISONS OF OUTCOMES OVER THE INFLUENZA SEASON

N Snow $^{1}$, K Downey ${ }^{2}$, WG Smith ${ }^{1,2}$

${ }^{1}$ Regional Paediatric Asthma Clinic (RPAC), Orillia Soldiers Memorial Hospital, Orillia; ${ }^{2}$ Department of Paediatrics, University of Toronto, Toronto, ON

PURPOSE: To audit the compliance of paediatric asthma patients with Influenza Vaccination during the 2013-2014 influenza season, where vaccinations was made available and assess relevant asthma related outcomes such as increased rate of unscheduled visits, antibiotic use and prednisone rescue, in asthmatic children who were not immunized for Influenza vs. those immunized.

METHODS: An audit of consecutive patients during the two influenza seasons was undertaken.

RESULTS: For the 2012-2013 influenza season, a total of 193 patients were audited. Of the total, $24 \%$ received the influenza vaccination. The 2013-2014 year audit indicated that 383 children were offered immunization and 268 agreed for a rate of $59 \%$.

The only variable changed during this second year of audit was the availability of the influenza immunization given by the RRT (CAE) at the clinic at the time of the visit.

CONCLUSIONS: By addressing the potential barriers to influenza immunization and offering immunization at the clinic, there was an increased uptake of the vaccine from $24 \%$ in $2012-2013$ to $59 \%$ in 2013-2014. We also documented the increased rate of unscheduled visits, antibiotic use and prednisone rescue, in asthmatic children who were not immunized for Influenza.

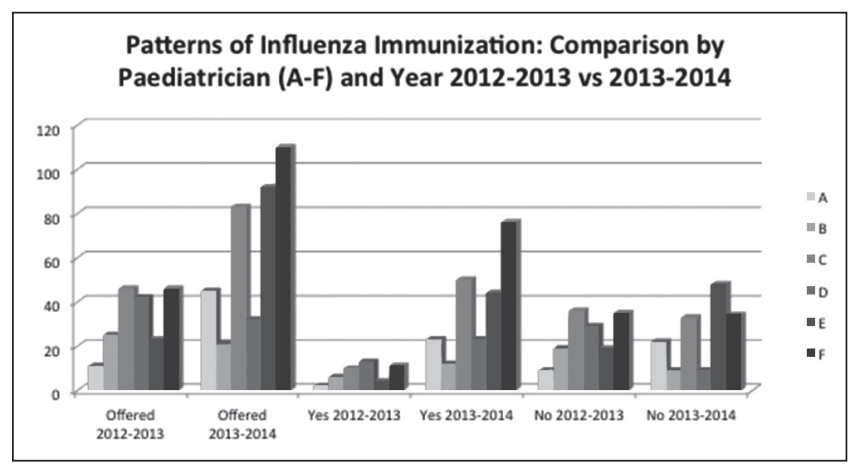

In the 2012-2013 audit year, 193 children were offered the influenza Vaccine at the clinic; 46 (23.6\%) said "Yes". In the 2013-2014 audit, 89 of the same children were back for follow- up visits for their asthma and 79 (88.8\%) said "Yes", when vaccination was made available at their clinic visit.

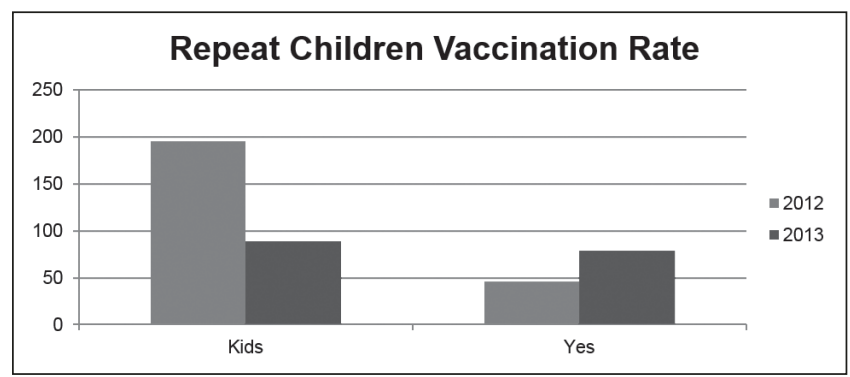

Conflicts of Interest: All cost was assumed by the Regional Paediatric Asthma Clinic, there are no conflicts of interest to declare.

38 - CRC2015-053

PLASTIC BRONCHITIS: A STICKY SITUATION

MFA Wright, A Kapur, DF Wensley

Department of Pediatric Respiratory Medicine, BC Children's

Hospital, Vancouver, BC

RATIONALE: Plastic bronchitis is a rare condition characterised by formation of casts that can cause life-threatening airway obstruction. Associations include congenital heart disease and infective or inflammatory respiratory disorders. We describe a case of plastic bronchitis in a child with acute severe asthma, and discuss options for management.

METHODS: A previously well 18-month old girl was admitted to hospital with respiratory distress and wheeze secondary to rhinovirus infection. Following initial response to conventional asthma management she acutely deteriorated with increased respiratory distress, hypoxia and acidosis. Despite use of intravenous bronchodilators she required intubation and mechanical ventilation. Ventilation was difficult and she developed a worsening respiratory acidosis $\left(\mathrm{pH} 7.05, \mathrm{PCO}_{2} 95 \mathrm{mmHg}\right)$. Repeat x-ray showed complete collapse of the left lung and right upper lobe.Emergency bronchoscopy was performed, at which a tenacious mucus plug was found to be obstructing the left main bronchus, and was successfully extracted. Postprocedural $x$-ray showed improved aeration bilaterally, associated with a marked improvement in acid-base status and ventilatory requirements. The child was extubated the next day and made a complete recovery.

RESULTS: Bronchoscopy is the mainstay of diagnosis and management in acute episodes of plastic bronchitis, and can be life-saving. However, casts may be too friable to be removed by forceps or too thick to be removed by suction. Cast fragmentation using mucolytic or fibrinolytic agents, either by endotracheal instillation or inhalation, can be effective in such circumstances. Recurrence rates are high amongst successfully treated cases. Longterm management options that have been described with variable success include azithromycin, inhaled mucolytics, and thoracic duct ligation.

CONCLUSION: Plastic bronchitis should be considered in cases of infective or inflammatory respiratory illnesses with acute clinical or radiological deterioration. Timely cast removal can be life-saving. Optimising control of the underlying disease is essential in order to minimise recurrence risk.

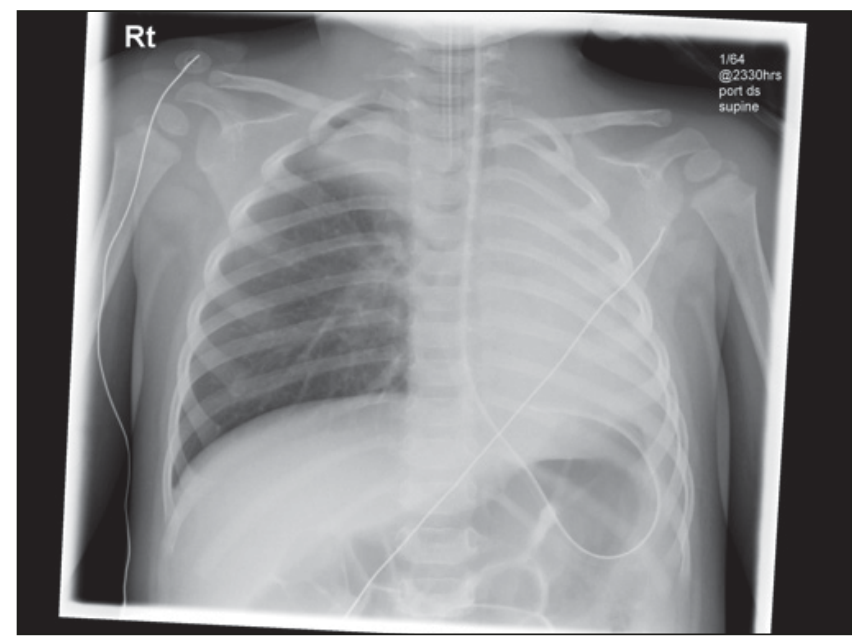

Figure 1) Pre-bronchoscopy chest $x$-ray

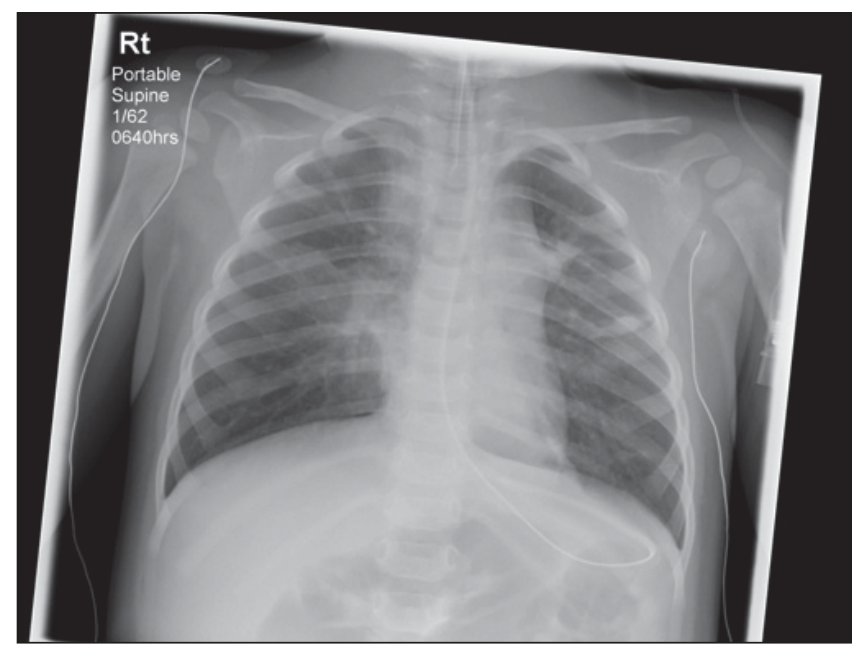

Figure 2) Post-bronchoscopy chest $x$-ray 


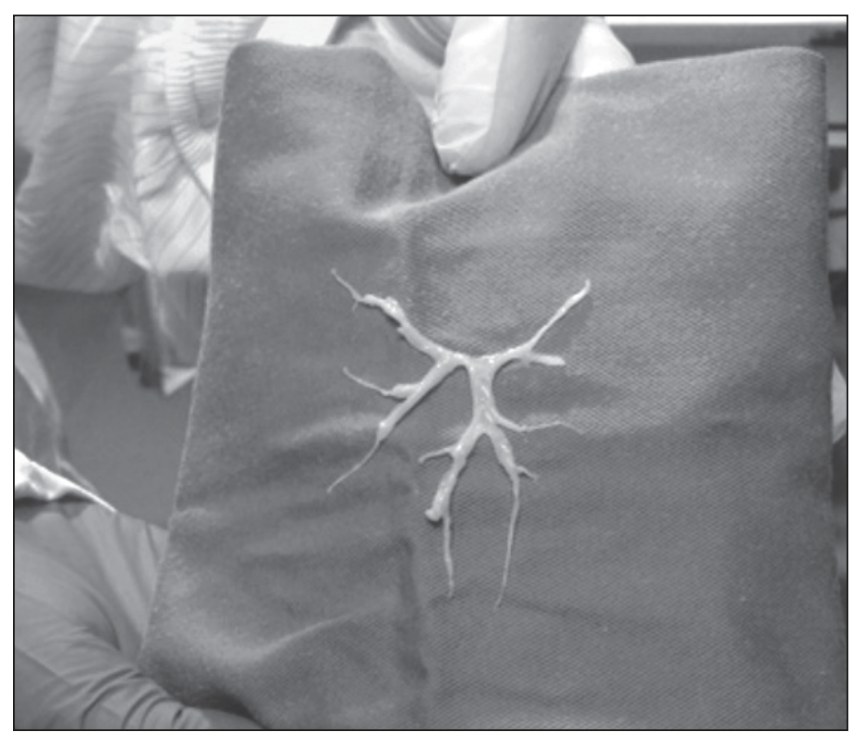

Figure 3) Cast removed at bronchoscopy

\section{Rehabilitation}

\section{9 - CRC2015-045 \\ COMBINED EXERCISE IS BENEFICIAL FOR GLYCEMIC CONTROL IN CF}

N Beaudoin ${ }^{1}$, G Bouvet ${ }^{1}$, Y Berthiaume ${ }^{1,2}$, R Rabasa-Lhoret ${ }^{1,2,3}$

${ }^{1}$ Institut de recherches cliniques de Montréal (IRCM); ${ }^{2}$ Department of Medicine; ${ }^{3}$ Department of Nutrition, Université de Montreal, Montreal, QC

BACKGROUND: Cystic fibrosis (CF) is one of the most common rare diseases in Quebec with a median survival age of 49 . However, the improvement in life expectancy is associated with the emergence of secondary complications such as cystic fibrosis related diabetes (CFRD). Present in 25-40\% of adults, and increased up to 6 times the risk of morbidity and mortality. Interestingly, combined exercise program (aerobic and resistance) improved glycemic control in patients with type II diabetes. OBJECTIVE: The aim of the study was to determine whether a combined exercise program is beneficial to improve the abnormal glucose tolerance and glycemic control in CF patients.

METHOD: $14 \mathrm{CF}$ with abnormal glucose tolerance were recruited for this study (age: $33 \pm 10$ years, $\mathrm{FEV}_{1} 71.8 \%$ pred $\pm 9.3 \%$, BMI $22.58 \pm 2.5 \mathrm{~kg} / \mathrm{m}^{2}$ ). Participants were randomly assigned to a control or exercise group. Participants in the exercise group received a combined exercise program for a period of 12 weeks, including 3 sessions/week, for 40 to 60 minutes. The following tests were used to evaluate the impact of exercise, pre and post intervention: $\mathrm{VO}_{2} \max$, oral glucose tolerance test (OGTT), muscular endurance and quality of life (CFQ-R). Preliminary analysis of the first 9 patients (exercise $n=6$, control $n=3$ ) showed that participants who adhered and completed the exercise program improved their 2-hour glucose $(-2.1 \mathrm{mmol} / \mathrm{L} ; \mathrm{p}=0.03)$. No changes were observed on other measures after the program.

CONCLUSION: Combined exercises program appears to improve glycemic control in CF patients. A longer period of intervention could be useful to show changes in quality of life and muscular endurance tests.

Financial Support: This work was supported by the Chaire J-A DeSève award by Dr Rabasa-Lhoret and Chaire Lamarre-Gosselin award by Dr Berthiaume.
40 - CRC2015-019

ADDRESSING DYSFUNCTIONAL BREATHING PATTERNS AS A CONTRIBUTOR TO DISPROPORTIONATE OR UNEXPLAINED DYSPNEA: A CASE SERIES

\section{LDeMars, B Walker}

Division of Respirology, Department of Medicine, University of

Calgary, Calgary, AB

BACKGROUND: Studies have shown that dysfunctional breathing (DB) may be associated with poorly controlled asthma. Subsequently, DB on its own may be more disabling than well-controlled asthma, and may be a contributing factor in medically unexplained dyspnea and other symptoms. Symptoms of DB have been shown to be diminished by various breathing retraining techniques.

CASE SERIES: Three patients with disproportionate or unexplained dyspnea were referred for a breathing assessment and retraining. While each patient's medical backgrounds differed, all three reported decreased quality of life due to shortness of breath. Objectively, they demonstrated increased accessory muscle use, lower $\mathrm{ETCO}_{2}$ levels and a decreased exhale component to their breathing. Treatment was delivered one-on-one with a physiotherapist trained in breathing retraining and focused on addressing each individual's unique breathing patterns. Capnography was used as realtime feedback to ensure that instructions on breathing pattern was appropriate for each person. Focus was on diaphragmatic, low volume effortless breathing at rest, and adaptability within postural, physical and emotional challenges. All three patients reported decreased symptoms, decreased medication use (where applicable), improved quality of life and restored ability to participate in activities.

DISCUSSION: Dysfunctional breathing disrupts the biomechanical, biochemical and often, the psychological component of breathing, and can contribute to increased sensations of shortness of breath and anxiety. Breathing retraining has the ability to address all three aspects of DB and may assist in decreasing symptoms, improving quality of life and enhancing self-management.

CONCLUSION: Dysfunctional breathing may be a clinically relevant aspect to unexplained or disproportionate dyspnea. Including breathing retraining in this patient population may prove to be beneficial as it can reduce unscheduled physician or specialist visits and empower individuals in self-management. Recognizing DB as a component of unexplained dyspnea may also provide a valuable piece of the puzzle for hard to manage cases.

Financial Support: None.

\section{1 - CRC2015-015}

BARRIERS AND FACILITATORS OF COMMUNITY-BASED EXERCISE: PERSPECTIVES OF INDIVIDUALS WITH HEART FAILURE, COPD, AND THEIR HEALTHCARE PROVIDERS L Desveaux $^{1,2}$, R Goldstein ${ }^{2}$, D Brooks ${ }^{2,3}$

${ }^{1}$ Graduate Department of Rehabilitation Science, Faculty of Medicine, University of Toronto; ${ }^{2}$ Department of Respiratory Medicine, West Park Healthcare Centre; ${ }^{3}$ Department of Physical Therapy, Faculty of Medicine, University of Toronto, Toronto, ON RATIONALE: Non-adherence to exercise programs following formal rehabilitation is one of the main factors associated with function for individuals with chronic disease. The objectives of this study were to: (1) describe the barriers and facilitators to program participation in a community-based exercise program from the perspective of individuals with chronic obstructive pulmonary disease (COPD), heart failure (HF), and their healthcare providers (HCP); and (2) to compare the perceptions of individuals with HF and COPD to HCP.

METHODS: Semi-structured interviews were conducted with 33 patients. A cross-sectional survey was administered to 19 HCP. Frequency distributions were obtained for all demographic characteristics and to describe perceived barriers and facilitators. Chi-squared tests were performed to compare perceived barriers and facilitators between groups.

RESULTS: Individuals with HF and COPD identified cost, severity of symptoms, and a lack of HCP support as the primary barriers to participation. Healthcare providers perceived severity of symptoms, lack of motivation, and a lack of HCP support to be the primary barriers. Patients reported that 
access to a case manager, a condition-specific program, and HCP support were primary facilitators, while HCP perceived HCP referral, social support, and confidence to have the most influence. HCP rated barriers as having a greater impact than individuals with HF and COPD, while both groups perceived facilitators to have a similar impact.

CONCLUSIONS: Healthcare providers perceive more barriers to participation and perceive them to have a greater impact than their patients with $\mathrm{HF}$ and COPD. Both groups perceive facilitators to have a strong impact on participation.

Financial Support: Laura Desveaux is supported by a CRHP Fellowship and an Ontario Graduate Award. Dina Brooks is supported by a Canada Research Chair.

\section{2 - CRC2015-061 PREDICTORS OF ENDURANCE TRAINING ATTENDANCE AND COMPLIANCE DURING PULMONARY REHABILITATION FOR COPD: A PILOT STUDY}

K Duckworth ${ }^{1,2}$, V Pepin 2,3, R Wardini2,3, AK Rizk ${ }^{2,3}$, S Bacon ${ }^{2,3}$, K Lavoie ${ }^{4}$, G Moullec ${ }^{4}$

${ }^{1}$ Université de Sherbrooke; ${ }^{2}$ Hôpital du Sacré-Coeur de Montréal;

${ }^{3}$ Concordia University; ${ }^{4}$ University of Quebec at Montreal, Montreal, QC

RATIONALE: Endurance exercise training is considered the cornerstone of pulmonary rehabilitation (PR) for chronic obstructive pulmonary disease (COPD). Its effectiveness depends on patients attending PR sessions, but also on their performing aerobic exercises in compliance with the prescribed intensity and duration. However, little is known about predictors of adherence to PR where only attendance is usually measured. The purpose of this pilot study was to investigate whether depression symptomatology predicts both attendance and compliance to aerobic exercise training.

METHODS: Thirty-six patients (64\% female) with stable COPD were enrolled in a 12-week 36-session supervised exercise intervention in the context of a PR program. Patients were randomized to one of three groups of varying exercise intensity. They underwent pulmonary function testing, an incremental cycling exercise test, completed the Beck Depression Inventory-II (BDI), Anxiety Sensitivity Index, Exercise Self-Efficacy Scale, Multidimensional Health Locus of Control, and provided demographic information. Attendance was defined as \% sessions attended. Compliance was defined as $\%$ of endurance training time at prescribed target heart rate (THR).

RESULTS: M \% (SD) attendance was 74\% (28). M \% (SD) compliance to THR was $76 \%$ (34). M (SD) BDI score was 9 (7). Bivariate Pearson correlations revealed that BDI correlated with THR compliance $(r=-0.350$, $\mathrm{p}=0.037)$ but not attendance $(\mathrm{r}=0.018, \mathrm{p}=0.919)$. Only \% pred. $\mathrm{FEV}_{1}$ correlated with attendance $(\mathrm{r}=0.439, \mathrm{p}=0.007)$. In standard multiple linear regression, $\mathrm{FEV}_{1} \%$ and cohabiting emerged as moderate predictors of attendance, whereas BDI score and sex were moderate predictors of THR compliance.

CONCLUSION: Predictors of attendance and compliance to exercise training may be different. This might be an important consideration is understanding and evaluation of poor outcomes in PR.

Financial Support: This work was supported by operating grants from the Fonds de recherche du Québec - Santé (FRQ-S) [grant number 12505] and the Canadian Lung Association - Canadian Respiratory Health Professionals [no assigned grant number].

\section{3 - CRC2015-038}

RELATIONSHIP BETWEEN ANXIETY, DEPRESSION, ILLNESS PERCEPTIONS AND OUTCOMES OF PULMONARY REHABILITATION FOR INDIVIDUALS WITH CHRONIC OBSTRUCTIVE PULMONARY DISEASE

KJ Horvey, S Butcher, D Marciniuk, D Goodridge, L Brawley

University of Saskatchewan, Saskatoon SK

RATIONALE: Individuals with chronic obstructive pulmonary disease (COPD) frequently experience symptoms of depression and anxiety. These symptoms result in an increased risk of acute exacerbations and death. Pulmonary rehabilitation (PR) can improve both depression and anxiety in individuals with COPD. Illness perceptions have been shown to impact quality of life (QOL) in patients with COPD. The interrelationship between these variables was examined.

METHODS: Sixteen participants with a diagnosis of COPD were recruited upon admission to the Saskatoon Pulmonary Rehab Program. Measures of anxiety and depression, health related QOL, shortness of breath (SOB) (both exertional and general), illness perceptions, and daily physical activity (PA) (via accelerometer and/or activity log) were collected upon admission to PR. Six minute walk test results were obtained from the participants' PR records. Correlations were completed looking at all independent variables and their relationship with the dependent variables.

RESULTS: Higher levels of anxiety were correlated with lower QOL $(p<0.05)$ and higher general SOB $(p<0.01)$. Higher levels of depression were correlated with higher exertional SOB $(p<0.05)$, lower QOL $(p<0.01)$, higher general SOB $(p<0.05)$, and more negative illness perceptions $(p=0.01)$. More negative illness perceptions were correlated with higher exertional SOB $(p<0.01)$, and lower QOL $(p<0.05)$. Lower levels of daily PA were correlated with higher levels of SOB $(p<0.05)$. Six minute walk test results had no significant correlations.

CONCLUSIONS: Higher levels of anxiety and depression, as well as negative illness perceptions in individuals with COPD attending PR were associated with higher levels of dyspnea and lower QOL but not significantly related to lower levels of physical activity.

\section{4 - CRC2015-022 MECHANISMS UNDERLYING PHYSIOLOGICAL LIMITATIONS DURING ARM ACTIVITY IN INDIVIDUALS WITH COPD - A SYSTEMATIC REVIEW}

T Janaudis-Ferreira ${ }^{1,2}$, V Pereira de Lima ${ }^{1,3,4}$, VC Iamonti ${ }^{5}$

${ }^{1}$ Respiratory Medicine, West Park Healthcare Centre; ${ }^{2}$ Department of Physical Therapy, University of Toronto, Toronto, ON ${ }^{3}$ Department of Physical Therapy, Federal University of Minas Gerais; ${ }^{4}$ Department of Physical Therapy, Federal University of Vales do Jequitinhonha and Mucuri, Minas Gerais; ${ }^{5}$ Department of Respiratory Disease, University of Sao Paulo, Sao Paulo, Brasil BACKGROUND: The purpose of this systematic review (SR) was to determine the mechanisms underlying physiological limitations during arm activity in individuals with chronic obstructive pulmonary disease (COPD). The specific objective was to describe cardiorespiratory responses, symptoms, chest wall kinematics, muscle activity and lung volumes during arm activity in individuals with COPD relative to the responses of healthy controls.

METHODS: Original articles that compared cardiorespiratory responses, symptoms, muscle activity, chest wall kinematics and lung function during arm activity between individuals with COPD and healthy controls were identified after searches of 5 electronic databases and reference lists of pertinent articles. Two reviewers performed the electronic and hand searches with one screening titles and abstracts. Two investigators screened the full-texts to determine eligibility for inclusion. One reviewer performed the data extraction and tabulation using a standardized form with a second reviewer double-checking the data extracted.

RESULTS: A total of 576 articles were identified. Of those, 6 met the inclusion criteria. Four articles compared cardiorespiratory responses between individuals with COPD and healthy controls during peak arm exercise. Reduced cardiorespiratory responses (e.g. oxygen consumption, minute ventilation, respiratory and heart rate) in individuals with COPD compared to health controls were evident. Compared to healthy controls, arm activity increased dyspnea and hyperinflation during peak arm exercise in individuals with COPD. Increased effort of the trapezius and biceps muscles during arm activities was found in COPD compared to controls. Chest wall kinematics was not assessed in any of the included studies.

CONCLUSIONS: There is limited evidence for mechanisms underlying physiological limitations during arm activity in individuals with COPD. Findings of this SR suggest that individuals with COPD have decreased cardiorespiratory responses during peak arm exercise compared to controls but increased dyspnea, hyperinflation and arm muscle effort.

Financial Support: Vanessa Lima holds a scholarship from CAPES/BrazilCoordenação de Aperfeiçoamento de Pessoal de Nível Superior. No: 99999.012323/2013-06. 
45 - CRC2015-012

DISTRACTIVE AUDITORY STIMULI IN THE FORM OF MUSIC IN INDIVIDUALS WITH CHRONIC OBSTRUCTIVE PULMONARY DISEASE - A SYSTEMATIC REVIEW

AL Lee $^{1,2}$, L Desveaux ${ }^{1,2}$, RS Goldstein ${ }^{1,2,3}$, D Brooks ${ }^{1,2}$ ${ }^{1}$ Respiratory Medicine, West Park Healthcare Centre; ${ }^{2}$ Department of Physical Therapy; ${ }^{3}$ Department of Medicine, University of Toronto, Toronto, ON

RATIONALE: Music has been used as a distractive auditory stimulus (DAS) in patients with chronic obstructive pulmonary disease (COPD), but its effects are unclear. This systematic review aimed to establish the effect of DAS on exercise capacity, symptoms and health-related quality of life (HRQOL) under three conditions: 1) during exercise training; 2) during exercise testing, and 3) as a strategy for symptom management at rest. METHODS: Randomized controlled or cross-over trials as well as cohort studies of DAS during exercise training, formal exercise testing and for symptom management among individuals with COPD, were identified following the search of seven databases. Two reviewers independently assessed study quality. Weighted mean differences (WMD) with 95\% CI were calculated using a random-effects model.

RESULTS: A total of 13 studies were included, 12 of which were randomized controlled or cross-over trials, with a total of 415 participants. DAS increased exercise capacity when applied over at least two months of exercise training (WMD of $94 \mathrm{~m}$ [95\% CI 38 to $151 \mathrm{~m}]$ ). HRQOL improved only after a training duration of three months. Less dyspnea was noted with DAS during exercise training but this was not consistently observed in short term exercise testing or as a symptom management strategy at rest. CONCLUSIONS: DAS appears to reduce symptoms of dyspnea and fatigue when utilized during exercise training, with benefits observed in exercise capacity and HRQOL. When applied during exercise testing, the effects on exercise capacity and symptoms and as a strategy for symptom management at rest are inconsistent.

Financial Support: None.

46 - CRC2015-006

FEASIBILITY OF ELECTRICAL MUSCLE STIMULATION IN LONG-TERM MECHANICALLY VENTILATED PATIENTS IN MEDICAL-SURGICAL INTENSIVE CARE UNIT

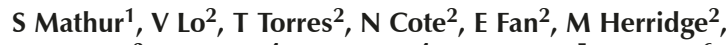
P Mendes ${ }^{3}$, D Dance 4 , J Flannery ${ }^{4}$, J Cameron ${ }^{5}$, W Gage ${ }^{6}$

${ }^{1}$ Department of Physical Therapy, University of Toronto; ${ }^{2}$ University Health Network - Toronto General Hospital; ${ }^{3}$ Graduate

Department of Rehabilitation Sciences, University of Toronto;

${ }^{4}$ University Health Network - Toronto Rehabilitation Institute; Department of Occupational Science \& Occupational Therapy, University of Toronto; ${ }^{6}$ School of Kinesiology \& Health Science, York University, Toronto, ON

RATIONALE: Electrical muscle stimulation (EMS) may preserve muscle mass during critical illness. This study aimed to determine feasibility of 1) administering EMS: number of sessions completed, proportion of dropouts, level of muscle contraction achieved and adverse events; and 2) obtaining ultrasound images of muscle thickness.

METHODS: Randomized controlled trial comparing EMS to sham treatment in critically ill patients, mechanically ventilated for $>7$ days. EMS was delivered to the quadriceps and gluteals, twice per day ( $30 \mathrm{~min} / \mathrm{session})$ 5 days/week for 4 weeks. The primary outcome was ultrasound imaging to assess muscle thickness of the quadriceps at baseline, 2 and 4 weeks.

RESULTS: Twenty-four subjects were enrolled between July 2012 and Oct 2013 (16 male; $51 \pm 18$ years). Baseline assessment and randomization occurred a mean (SD) $16 \pm 9$ days from ICU admission. $50 \%$ of subjects completed 2 weeks of treatment and 5 additional subjects completed 4 weeks. Reasons for dropout prior to 2 weeks were death $(n=2)$, transfer out of ICU $(n=4)$ and skin breakdown unrelated to EMS $(n=1)$. On average, subjects completed $22 \pm 11$ sessions of EMS (range 4 to 39 sessions). The amplitude of EMS varied per session and ranged from minimal dosage (11mA) to maximal output of the stimulator $(160 \mathrm{~mA})$. The majority of subjects experienced small muscle contractions (ratings $=1-2$ on a 5 point scale; $0=$ no visible contraction and $5=$ strong contraction). There were no adverse events. $88 \%$ of ultrasound images had adequate quality for analysis.

CONCLUSIONS: EMS appears to be feasible to apply in a long-term, mechanically ventilated population however mortality and early ICU discharge affected protocol completion. Ultrasound imaging is a quantitative outcome for EMS trials and was found to have sufficient quality for analysis. Future studies should examining factors which affect muscle contractility in critically ill patients.

Financial Support: Allied Health Research Grant (University Health Network), Canadian Respiratory Health Professional Research Grant (The Lung Association).

\section{7 - CRC2015-013}

CARDIOPULMONARY RESPONSES TO SHORT BOUTS OF STRENGTH EXERCISES IN PEOPLE WITH COPD: A COMPARISON OF EXERCISE INTENSITIES

P Robles ${ }^{1,2}$, T Araujo ${ }^{1}$, T Janaudis-Ferreira ${ }^{1}$, K Zabjek ${ }^{2}$, D Brooks ${ }^{1,2}$, Sunita Mathur ${ }^{1,2}$, Susan Marzolini ${ }^{3}$

${ }^{1}$ Respiratory Medicine, West Park Healthcare Centre; ${ }^{2}$ Graduate Department of Rehabilitation Science and Department of Physical Therapy, University of Toronto; ${ }^{3}$ Cardiac Rehabilitation \&

Secondary Prevention, Toronto Rehabilitation Institute, Toronto, ON There are no specific guidelines for strength training in people with COPD and an important gap exists regarding the prescription of training intensity. RATIONALE: To assess acute cardiopulmonary responses to low- and high-intensity strength training exercises in people with COPD and compare their responses to age-matched healthy adults.

METHOD: Participants ( $n=7$ per group) performed one set of 10 repetitions of double leg extensions and double arm forward elevations at $40 \%$ and $80 \%$ of one repetition maximum. Minute ventilation (VE) and oxygen uptake $\left(\mathrm{VO}_{2}\right)$ were collected during a 20 -minute rest (prior to exercise) and during each set of exercise. Values were expressed as absolute and relative (percentage of peak aerobic capacity). Heart rate (HR), blood pressure (BP), oxygen saturation $\left(\mathrm{SpO}_{2}\right)$ and perceived exertion (RPE) were monitored before and after each set of exercise.

RESULTS: Individuals with COPD showed no differences in absolute VE and $\mathrm{VO} 2$ achieved during high- versus low-intensity leg extension or arm elevation. RPE was greater in COPD after high-compared to low-intensity leg extension [4 (1.4) vs. $2(1) ; \mathrm{p}<0.005)]$ and arm elevation [3 (2) vs. $1(1.4) ; \mathrm{p}<0.005)]$. Individuals with COPD presented higher relative VE and $\mathrm{VO}_{2}$ when compared to controls $(\mathrm{p}<0.001)$, but similar RPE scores. No differences in $\mathrm{HR}, \mathrm{BP}$ and $\mathrm{SpO}_{2}$ between high and low intensities in COPD; and their responses were similar to controls.

CONCLUSIONS: Participants with COPD are working at a higher percentage of their maximum aerobic capacity during strength training regardless of intensity, although their perceived exertion is comparable to healthy individuals.

Financial Support: Work supported by The Canadian Respiratory Health Professionals Society, The Lung Association.

\section{$48 \cdot$ CRC2015-011 \\ A COMPARISON OF MUSCLE STRENGTH ASSESSMENT USING MRC SCALE AND COMPUTERIZED DYNAMOMETRY IN PATIENTS FOLLOWING ICU DISCHARGE}

L Souza-Barros ${ }^{1}$, L Lopez-Hernandez ${ }^{1}$, T Araujo ${ }^{1}$, J Cameron ${ }^{1}$, M Herridge $^{1,2}, \mathrm{~S}^{1}$ Mathur $^{1}$

${ }^{1}$ University of Toronto; ${ }^{2}$ University Health Network, Toronto, ON PURPOSE: Medical Research Council (MRC) scale is used as a bedside measure of muscle strength in the intensive care unit (ICU). However, MRC may have limited sensitivity in assessing muscle weakness in longterm follow up after ICU discharge. The purpose of this study was to examine the relationship between muscle strength assessed using the MRC with peak torque measured using computerized dynamometry in patients following ICU discharge.

METHODS: 28 subjects (21 males; age $52 \pm 19$ yrs) were recruited from an ongoing study of long-term outcomes following critical illness (Towards RECOVER). Muscle strength of the knee extensors (KE), ankle dorsiflexors 
(DF) and shoulder flexors (SF) were measured using the MRC scale and isometric peak torque using the Biodex dynamometer at $3(n=20), 6(n=18)$ and $12(\mathrm{n}=9)$ months post-ICU discharge. MRC was graded from 0 (no muscle contraction) to 5 (full strength against gravity, against maximal resistance). Isometric peak torque (Newton-metres, $\mathrm{Nm}$ ) was measured from five maximal voluntary isometric contractions of each muscle group. Normative values for isometric peak torque from 17 healthy control subjects ( 9 males; age $44 \pm 16$ yrs) were included for comparison.

RESULTS: No significant correlations were found between peak torque and MRC scores at 3, 6 or 12 months for any muscle group ( $r=0.12$ to 0.24 ; $\mathrm{p}>0.05)$. A discrepancy was noted between MRC grade and muscle weakness detected by peak torque measures. For example at 3 months, subjects with MRC grade 4 had KE peak torque ranging from 26 to $107 \%$ of predicted values; and MRC grade 5 ranged from 34 to $133 \%$ predicted. CONCLUSION: MRC scale did not provide adequate sensitivity to detect muscle weakness in all patients post ICU-discharge. Future studies on long-term recovery and post-ICU rehabilitation should consider the use of computerized dynamometry to assess changes in muscle function. Financial Support: None

\section{Sleep and Ventilation}

\section{9 - CRC2015-050}

\section{THE DEVELOPMENT OF A TOOL TO ASSESS CAREGIVER} KNOWLEDGE AND SKILLS NEEDED TO SAFELY CARE FOR CHILDREN RECEIVING INVASIVE LONG-TERM MECHANICAL VENTILATION AT HOME: THE KIDS VENT STUDY

R Amin 1,2, C Parshuram 2,3, J Kelso 4,5 A Lim 4,5, D Mateos ${ }^{6,7}$, I Mitchell ${ }^{8,9}$, H Patel ${ }^{10,11}$, M Roy ${ }^{4,5}$, F Syed ${ }^{1,2}$, R Troini ${ }^{10,11,12}$, D Wensley ${ }^{13,14}$, L Rose ${ }^{2,15}$

${ }^{1}$ Division of Respiratory Medicine, The Hospital for Sick Children; ${ }^{2}$ University of Toronto; ${ }^{3}$ Division of Critical Care Medicine, The Hospital for Sick Children, Toronto; ${ }^{4}$ McMaster Children's Hospital; ${ }^{5}$ McMaster University, Hamilton, ON; ${ }^{6}$ IWK Health Center; ${ }^{7}$ Dalhousie University, Halifax, NS; ${ }^{8}$ Alberta Children's Hospital; ${ }^{9}$ University of Calgary, Calgary, AB; ${ }^{10}$ The Montreal Children's Hospital; ${ }^{11}$ McGill University; ${ }^{12}$ National Program for Home Ventilatory Assistance, Montreal, QC; ${ }^{13} \mathrm{BC}$ Children's Hospital; ${ }^{14}$ University of British Columbia, Vancouver, BC; ${ }^{15}$ Bloomberg Faculty of Nursing, Toronto, ON

BACKGROUND: Parents undergo extensive caregiver training prior to hospital discharge but are not reassessed in the home environment on an ongoing basis. This is a serious concern as these children are at risk of morbidity and death given their medical complexity. Our aim was to formally develop a tool based on a national consensus, to assess the caregivers' knowledge and skills which are essential to care for a ventilator assisted child (VAC) both at the time of initial discharge home as well as for their ongoing care.

METHODS: A prospective study was conducted at SickKids, Toronto, Canada. We planned a 4 step process including: 1 ) assembly of a national, interprofessional group with pediatric home ventilation expertise; 2) item generation via a scoping literature review and compilation of local documents used by home ventilation programs; 3 ) item reduction by a national Delphi process in accordance with the Dillman method; 4) sensibility assessment by clinicians and family caregivers to determine completeness and usability.

RESULTS: The study was conducted from January 2012 to present. One hundred and thirty two pediatric home ventilation clinicians from 12 institutions across Canada were involved. After item generation, the KIDS VENT tool was comprised of 18 domains and 255 items. The overall response rate for Delphi round 1 was 95/132 (72\%). Nine items were removed after round 1 . The overall response rate for Delphi round 2 was $80 / 95$ (84\%). No items were removed from round 2. After Delphi round 2, the KIDS VENT tool was comprised of 18 domains and 246 items. The sensibility assessment is ongoing and results will be available by the time of the meeting.
CONCLUSIONS: Future work is needed to see if standardized, ongoing competency assessments improve the quality of care provided by parental caregivers and subsequently lead to decreased morbidity and mortality.

Financial Support: Norm Saunders Complex Care award, Sick Kids, Toronto, Ontario.

\section{0 - CRC2015-043}

A 15 MONTHS OLD BOY WITH CORNELIA DE LANGE SYNDROME AND CENTRAL SLEEP APNEA: A CASE REPORT $\underline{\text { S Bin-Hasan }}{ }^{1,2}$, D Reppucci ${ }^{1,2}$, MJ Smith ${ }^{3,4}$, Z Bismilla ${ }^{2,5}$, N Saunders ${ }^{2}, 5$, R Amin ${ }^{1,2}$

${ }^{1}$ Division of Respiratory Medicine, The Hospital for Sick Children; ${ }^{2}$ University of Toronto, Toronto, ON; ${ }^{3}$ Janeway Children's Health and Rehabilitation Centre; ${ }^{4}$ Department of Pediatrics, Memorial University of Newfoundland, St John's, NL; ${ }^{5}$ Department of Paediatrics, The Hospital for Sick Children, Toronto, ON BACKGROUND: Cornelia de Lange Syndrome (CdLS) is a rare genetic disorder with an incidence of 1:10000 to 1:50000. Sleep disturbances in CdLS have been reported in previous studies with a prevalence of 12 to $80 \%$ based on sleep questionnaires. However, PSG findings to confirm suspected SDB have not been previously reported in CdLS.

CASE REPORT: We present a 15 month old boy with CdLS who was referred to our institution for a second opinion due to recurrent episodes of acute respiratory failure requiring intermittent invasive mechanical ventilation over the preceding 6 months. His past medical history was significant for a cleft palate, previous supraglottoplasty for laryngomalacia, gastroesophageal reflux disease requiring fundoplication and an atrial septal defect (ASD). He had been on continuous supplemental oxygen by nasal prongs since the age of 8 months. A diagnostic workup was performed showing a normal barium swallow, Chest CT showing no parenchymal disease and an echocardiographically confirmed ASD. A brain MRI demonstrated cerebral parenchymal atrophy and hypoplasia in the bilateral frontal parietal regions and brainstem. There was no adenotonsillar hypertrophy on upper airway endoscopy. An overnight oximetry study on room air showed a desaturation index of 54.4/hr. On the polysomnogram (PSG), CSA (central apnea-hypopnea index of 19/hour) and nocturnal hypoventilation (transcutaneous $\mathrm{CO} 2>50 \mathrm{mmHg}$ for $53 \%$ of the night) were found in the absence of obstructive events. In consideration of the PSG findings non-invasive positive pressure ventilation was initiated and resulted in a significant improvement in the child's clinical status.

CONCLUSION: Children with CdLS and recurrent respiratory exacerbations and/or unexplained nocturnal oxygen desaturations should be screened for sleep disordered breathing. In the case of central sleep apnea, long-term ventilation should be discussed with the family because of the opportunity for early intervention to decrease morbidity and improve the quality of life of these children.

\section{1 - CRC2015-014}

\section{ACCESS TO ZZZ'S: A QUALITY IMPROVEMENT JOURNEY}

C Byblow ${ }^{1}, K_{\text {Kard }}^{2}$, B Pawlak ${ }^{1}$, PJ Hanly ${ }^{1,3}$, J Warren ${ }^{4}$,

SR Pendharkar 1,3,5

${ }^{1}$ Foothills Medical Centre Sleep Centre, University of Calgary; ${ }^{2}$ Clinical Quality Improvement, Calgary Zone, Alberta Health

Services; ${ }^{3}$ Department of Medicine, University of Calgary; ${ }^{4}$ Process Improvement, Alberta Health Services; ${ }^{5}$ Department of Community Health Sciences, University of Calgary, Calgary, AB

RATIONALE: Patients referred to FMC Sleep Centre experience excessive delays for assessment, with urgent and non-urgent patients waiting approximately 4 months and 19 months, respectively. Additionally, data collection practices made it difficult to measure if process changes were improving access. The objective of the Access to Zzz's quality improvement (QI) project was to decrease waiting times for urgent patients and improve measurement processes.

METHODS: The project team was comprised of clinical providers, nonclinical staff and operational leaders and was led by a QI consultant. Work to date has included: mapping of referral and triage and scheduling processes; data collection focused on demand, capacity, activity and delay for 
each clinical step; and PDSA (plan-do-study-act) cycles to test improvement opportunities.

RESULTS: Preliminary data revealed a number of opportunities for improvement. For example, incomplete referral information led to 32-day delay from patient referral to triage. Additionally, despite stable referral demand, there is high variability in sleep respirologist activity for sleep clinics. Furthermore, inefficient scheduling has resulted in weekly average of $18 \%$ of appointment slots remaining unfilled. A number of PDSA cycles have been completed or are underway to: standardize referral information; direct patients to appropriate providers with the appropriate level of urgency; and reduce variation in service delivery. Importantly, this work has promoted a 'culture of continuous improvement' among physicians, staff and administrators.

CONCLUSION: Given the challenges with access to diagnosis and treatment of sleep disorders, QI activities provide opportunities to evaluate current clinical and administrative practices. A systematic approach is required to identify opportunities for improvement, perform small tests of change, and measure effects on system performance. Although Access to Zzz's was specific to the FMC Sleep Centre, the findings related to referral practices, physician availability, scheduling inefficiencies, and the QI process are likely of interest to other sleep centres.

\section{$52 \cdot$ CRC2015-001 LONG-TERM NON-INVASIVE VENTILATION IN CHILDREN IN ALBERTA: OUTCOMES AND COMPLICATIONS \\ $\underline{\text { M Castro-Codesal }}{ }^{1}$, P Bedi ${ }^{1}$, D Olmstead ${ }^{1}$, G Bendiak ${ }^{2}$, S Katz ${ }^{3}$, J MacLean ${ }^{1}$ \\ ${ }^{1}$ Stollery Children's Hospital, University of Alberta, Edmonton; \\ ${ }^{2}$ Alberta Children's Hospital, University of Calgary, Calgary, AB; ${ }^{3}$ Children's Hospital of Eastern Ontario, University of Ottawa, Ottawa, ON}

RATIONALE: The use of non-invasive ventilation (NIV) in children has risen exponentially over the last decade. There is little data about outcomes and complications in Canada. The aim of this study is to examine the clinical course and outcomes for children started on NIV in Alberta.

METHODS: A retrospective chart review was performed for children using NIV $\geq 3$ months and cared for at the pediatric NIV programs in Alberta over the last 12 years. Clinic charts and sleep laboratory records were reviewed. Underlying conditions were divided into 4 categories: upper airway (UA), central nervous system (CNS), musculoskeletal (MSK), and pulmonary (PULM) diseases. Symptoms improvements and complications were extracted from clinical reports.

RESULTS: A total of 345 children using NIV were identified at the first site; 89 charts have been reviewed to date. The mean age of NIV initiation was $8.7 \pm 5.6$ years and $60 \%$ were male. UA was the predominant disease category with $57 \%$ of children, CNS 23\%, MSK $12.8 \%$, and PULM $7.0 \%$. G-tube and supplemental oxygen were used by $23.3 \%$ and $22 \%$ of children respectively. At 6-12 month follow up after NIV initiation, improvement in sleep (71\%), nocturnal breathing (73\%), mood/behaviour (41\%), learning/school performance (37\%), and quality of life (QOL; 64\%) were reported; data from the most recent visit showed the same pattern with no difference by disease category. Overall, complications were reported for $63 \%$ of children with no difference by disease category. Thirty-five percent of children have been discharged from the NIV program; $25 \%$ of discharges were because of discontinuing NIV. There were no significant differences by disease category for those who discontinued NIV therapy.

CONCLUSIONS: NIV use in children often subjectively improved sleep, breathing, and QOL. NIV was associated with frequent complications. Disease category did not seem to affect reported symptom improvements, complications or NIV discontinuation rates.

Financial Support: This project was awarded with the Deloitte and Stollery Foundation Clinical Research Fellowship and received support from the Women and Children's Health Research Institute (WCHRI).
$53 \cdot$ CRC2015-002

LONG-TERM NON-INVASIVE VENTILATION IN CHILDREN: TRENDS OF THE HOME VENTILATION PROGRAMS IN ALBERTA (2003-2014)

M Castro-Codesal ${ }^{1}$, P Bedi' ${ }^{1}$, D Olmstead ${ }^{1}$, G Bendiak ${ }^{2}$, S Katz ${ }^{3}$, J MacLean ${ }^{1}$

${ }^{1}$ Stollery Children's Hospital, University of Alberta, Edmonton;

2Alberta Children's Hospital, University of Calgary, Calgary, AB; ${ }^{3}$ Children's Hospital of Eastern Ontario, University of Ottawa, Ottawa, ON

RATIONALE: Rates of non-invasive ventilation (NIV) in children have increased worldwide but there is no data available in Alberta. The aim of this study is to describe the longitudinal trends of the pediatric NIV programs in Alberta.

METHODS: This is a retrospective review of outpatient medical charts and sleep laboratory records of all children receiving NIV for $\geq 3$ months and cared for through the NIV clinic. Data was subdivided into 4-year epochs, 2003-2006, 2007-2010, and 2011-2014.

RESULTS: We identified 345 children who commenced NIV during the 12-year period. We have reviewed 89 charts to date. The number of children starting NIV each year increased significantly across the epochs (Kruskal-Wallis, $\mathrm{p}<0.05$ ): 9 children started in the first epoch, 32 in the second and 48 in the third. Mean age of initiation across epochs differed; age was similar in the first and second epochs $(7.9 \pm 2.5 \mathrm{y}, 10.7 \pm 5.1 \mathrm{y})$ but lower in the third epoch compared to the second $(7.2 \pm 5.4 \mathrm{y}$; post-hoc ANOVA $p<0.05)$. Children $<2$ years of age were only represented in the third epoch (24). The reason for NIV initiation differed across epochs; for example, NIV was initiated after acute illness in 11\%, 13\% and 37\% respectively across epochs (Chi-square 10.33, p<0.05). Overall, $56 \%$ of children were started on continuous positive airway pressure (CPAP) versus $44 \%$ on Bilevel support. There was no difference on NIV type across epochs. The interface type changed across epochs with a higher proportion of nasal versus full-face mask over time $(6 \%, 27 \%, 67 \%$ respectively, Chisquare $15.6, \mathrm{p}<0.001)$.

CONCLUSIONS: NIV use in children has increased over time. More recently, younger children and infants are receiving NIV. While the type of ventilation has not changed over time, more nasal mask interfaces have been used. This interim analysis supports our trends in NIV are similar to those reported worldwide.

Financial Support: This project was awarded with the Deloitte and Stollery Foundation Clinical Research Fellowship and received support from the Women and Children's Health Research institute (WCHRI).

\section{$54 \cdot$ CRC2015-048}

MIND THE GAP: PAEDIATRIC TO ADULT HEALTH SERVICE TRANSITION EXPERIENCES OF YOUNG ADULTS REQUIRING DOMICILIARY LONG-TERM MECHANICAL VENTILATION (LTMV) AND THEIR FAMILY CAREGIVERS C Dale $^{1}$, J King ${ }^{2}$, S Katz ${ }^{3}$, R Amin ${ }^{4}$, M Nonoyama ${ }^{5}$, D McKim ${ }^{6}$, $\mathrm{J} \mathrm{Road}^{7}$, L Rose $^{1}$

${ }^{1}$ University of Toronto, Toronto; ${ }^{2}$ University of Ottawa; ${ }^{3}$ Children's Hospital of Eastern Ontario, University of Ottawa, Ottawa; ${ }^{4}$ The Hospital for Sick Children, University of Toronto, Toronto; ${ }^{5}$ University of Ontario, Institute of Technology, Oshawa; ${ }^{6}$ The Ottawa Hospital, University of Ottawa, Ottawa, ON; ${ }^{7}$ Vancouver General Hospital, University of British Columbia, Vancouver, BC; on behalf of the CANUVENT group

RATIONALE: Advances in health care including long-term mechanical ventilation (LTMV) have translated into more children with chronic health conditions or disabilities reaching adulthood. Successful transition from paediatric to adult health services is vital to long-term health and psychosocial outcomes. International research has identified important deficits in health transition experiences. The goal of this descriptive qualitative study was to explore paediatric to adult transitional experiences of domiciliary LTMV patients and family caregivers in Canada.

METHODS: Participants representing 14 paediatric to adult transitions were recruited through hospital and community respiratory clinics in British 
Columbia and Ontario. Semi-structured interviews were conducted with 13 family caregivers and 5 young adults (ages 17-21) receiving domiciliary LTMV. Interviews were transcribed verbatim and explored through qualitative methods to elucidate key elements of the transition experience.

RESULTS: Availability of adult health services was a central determinant of the transition experience. In some cases, there was no identified specialty provider to whom care could be transitioned thus inhibiting continuity of health services. Gaps in home care funding, communication, and trained community providers were cited as major transitional barriers. Service shortfalls intensified caregiver burden and a sense of social isolation in transition. Strategies to facilitate transition included team meetings, written care plans, and a central point of contact for health information.

CONCLUSIONS: Despite existing programs and models, transition from paediatric to adult health services remains challenging. Transition for those requiring domiciliary LTMV may be characterized by health service gaps. Improved health self-efficacy and satisfaction may be enhanced through a central point of contact whereby lay or professional navigators could assist individuals and families to identify transitional resources and information enabling informed decisions. Better understanding of effective transition programs is required to bridge the gap between paediatric and adult services and improve transition experiences in Canada.

Financial Support: CIHR.

Conflict of Interest: There are no conflicts of interest from any of the authors of this study.

\section{$55 \cdot$ CRC2015-028 \\ VENTILATOR SETTINGS ASSOCIATED WITH AVERAGE VOLUME-ASSURED PRESSURE SUPPORT (AVAPS) TOLERANCE IN ALS}

M Kaminska $^{1,2}{ }^{1}$, R Troini ${ }^{1}$, V Adam $^{1}$

${ }^{1}$ National Program for Home Ventilatory Assistance; ${ }^{2}$ Respiratory Epidemiology and Clinical Research Unit, McGill University Health Centre, Montreal, QC

RATIONALE: The average volume-assured pressure support (AVAPS) mode of non-invasive ventilation (NIV) is a barometric mode that autoadjusts the delivered inspiratory pressure (IPAP) to maintain a pre-specified tidal volume, potentially with greater stability of ventilation compared to the spontaneous-timed (ST) mode. Our aim was to assess tolerance to AVAPS in patients with amyotrophic lateral sclerosis (ALS) already on NIV in ST, and to identify ventilator settings associated with AVAPS intolerance.

METHODS: Ten ALS patients were switched from ST to AVAPS. The expiratory pressure (EPAP) was unchanged. The initial IPAPAVAPS range and target tidal volume (VT) were based on, respectively, the IPAPST and the mean VT attained in ST. Whenever needed, adjustments were made to maximize comfort. Mean and maximal IPAPAVAPS were obtained from the ventilator download after 2-4 weeks.

RESULTS: Three of 10 patients did not tolerate AVAPS due to excessive pressure; one had bulbar dysfunction. Target VT in six of the seven tolerant patients were $\leq 6 \mathrm{cc} / \mathrm{kg}$ ideal body weight, whereas in intolerant patients, VT was $>6 \mathrm{cc} / \mathrm{kg}$. The mean difference between the mean IPAPAVAPS and the set IPAPST was $-0.2 \mathrm{cmH}_{2} \mathrm{O}$ (range -1.8 to 2.3 ) in tolerant patients, and $1.4 \mathrm{cmH}_{2} \mathrm{O}(-1.1$ to 3.4$)$ in intolerant patients. The mean difference between the maximal IPAPAVAPS and the IPAPST was $1.8 \mathrm{cmH}_{2} \mathrm{O}(0$ to 4.0) in tolerant patients, and $3.6 \mathrm{cmH}_{2} \mathrm{O}(2.2$ to 5.0$)$ in intolerant patients. CONCLUSION: AVAPS is well tolerated in most ALS patients, using target VT $\leq 6 \mathrm{cc} / \mathrm{kg}$ ideal body weight. Intolerance appears to result from high IPAPAVAPS required to maintain a higher target VT. Intolerance may occur despite a mean IPAPAVAPS lower than IPAPST, if maximal IPAPAVAPS is higher. Additional studies will be needed to assess whether AVAPS might provide more stable ventilation throughout all sleep phases and as disease progresses in ALS.

Financial Support: None.

\section{6 - CRC2015-041}

TRANSITIONING FROM HOSPITAL TO HOME: THE EXPERIENCES OF ADULTS REQUIRING LONG TERM MECHANICAL VENTILATION (LTMV) AND THEIR FAMILY CAREGIVERS

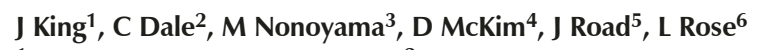

${ }^{1}$ University of Ottawa, Ottawa; ${ }^{2}$ University of Toronto, Toronto; ${ }^{3}$ University of Ontario, Institute of Technology, Oshawa; ${ }^{4}$ The Ottawa Hospital-University of Ottawa, Ottawa, ON; ${ }^{5}$ Vancouver General Hospital, University of British Columbia, Vancouver, BC; ${ }^{6}$ University of Toronto, Toronto, ON; on behalf of CANuVENT group RATIONALE: Advanced life support technologies have contributed to a growing population dependent on long term mechanical ventilation (LTMV). Although people receiving LTMV are increasingly discharged from hospital to home, little is known about this transition. The goal of this descriptive qualitative study was to elucidate the transitional experiences of people receiving LTMV and their family caregivers.

METHODS: Recruitment of participants occurred through hospital and community respiratory clinicians in Alberta, British Columbia, Ontario and Saskatchewan. Semi-structured telephone or home interviews were conducted with 20 adults receiving LTMV and 13 family caregivers. To foster reflexivity in analysis, regular team meetings were recorded, transcribed and reviewed to reach agreement on the developing themes.

RESULTS: Preliminary descriptive themes that have emerged include 'Mixed Expectations', 'Home as Hospital', 'Changing Roles and Responsibilities' and 'Social and Geographic Isolation'. From the perspective of adults receiving LTMV and their caregivers, there are not one but multiple transitions. For the adult receiving LTMV the more profound transition home on LTMV is conditioned by uncertainty in identity and supportive resources for daily living. While for family members, the more profound transition is moving from being a family member to primary caregiver. Participants described early uncertainties regarding their home management capacities and varying degrees of isolation in their transition.

CONCLUSIONS: Healthcare professionals may use these findings to improve sensitivity, understanding and opportunities for improving transition in a growing LTMV population. Potential resources warranting inquiry include the development of peer support for people receiving LTMV and their families, in addition to community outreach, to more effectively bridge clinical and domiciliary environments.

Financial Support: CIHR.

Conflict of Interest: None to report.

\section{$57 \cdot$ CRC2015-017 PNEUMOTHORAX IN VENTILATED NEUROMUSCULAR PATIENTS}

AHS Loewen ${ }^{1,2,3,4,5}$, R Tye 1,2, L Howie ${ }^{3}$, KL Fraser 4,5, KP Rimmer1,2,3,4 ${ }_{1}^{1}$ Peter Lougheed Center, Neuromuscular Respiratory Clinic, Alberta Health Services; ${ }^{2}$ South Health Campus, ALS Clinic, Alberta Health Services; ${ }^{3}$ Calgary Zone Chronic Ventilation Program, Alberta Health Services; ${ }^{4}$ Division of Respirology, Department of Medicine, University of Calgary; ${ }^{5}$ Foothills Medical Center Sleep Centre, Alberta Health Services, Calgary, AB

RATIONALE: In neuromuscular patients positive airway pressure ventilation and cough assistance are utilized routinely and may place patients at risk of pneumothorax.

METHODS: Retrospective chart review of six cases of pneumothorax in ventilated neuromuscular patients between the years 2011 to 2014 RESULTS: Six neuromuscular patients (diagnosis of ALS, limb girdle dystrophy, myotonic dystrophy, CAP myopathy and collagen 6-related myopathy) were reviewed. Mean FVC 1.3 L (35\% predicted), mean BMI 17. One patient was ventilated with tracheostomy, the remaining 5 noninvasively. Mean duration of positive pressure ventilation at time of the pneumothorax was 1.25 years. The invasively ventilated patient was on volume assist control, tidal volume $500 \mathrm{~mL}$, with peak inspiratory pressure $20 \mathrm{mmHg}$, PEEP 4, and was using mechanical insufflation-exsufflation. The remaining noninvasively ventilated patients had a mean IPAP of $19 \mathrm{cmH}_{2} \mathrm{O}$, mean EPAP $7 \mathrm{cmH}_{2} \mathrm{O}$, back up rate of 15 . These patients used 
lung volume recruitment for airway clearance ( 3 patients). 5 of 6 patients required chest tube placement and 4 of 6 had recurrent pneumothoraces. Two of these received chemical pleurodesis.

CONCLUSION: Although seldom reported pneumothorax occurs in neuromuscular patients receiving chronic positive pressure ventilation and cough assistance techniques. This raises the question of whether barotrauma or volutrauma can occur in patients with presumably normal lung compliance. Commonly decreased lung compliance is associated with risk of pneumothorax in ventilated patients. The overall BMI of these patients was low, it is possible that nutritional status can be associated with risk of pneumothorax. In one patient a collagen disorder was subsequently diagnosed, and this raises the interesting possibility of connective tissue disorders associated with neuromuscular disease.

Financial Support: None.

\section{$58 \cdot$ CRC2015-044}

VENTILATORY RESPONSES DURING STAGE I EXERCISE TESTS DO NOT CORRELATE TO PHOX2B GENOTYPE IN CHILDREN WITH CONGENITAL CENTRAL HYPOVENTILATION SYNDROME (CCHS)

WTH To $^{1,2}$, T Moraes ${ }^{1,2,3}$, JE Schneiderman ${ }^{1,3,5}$, R Amin $^{1,2,4}$ ${ }^{1}$ Division of Respiratory Medicine, Department of Pediatrics, The Hospital for Sick Children; ${ }^{2}$ Department of Pediatrics, University of Toronto; ${ }^{3}$ Physiology and Experimental Medicine, The Hospital for Sick Children; ${ }^{4}$ Child Health and Evaluative Sciences, The Hospital for Sick Children; ${ }^{5}$ Faculty of Kinesiology \& Physical Education, University of Toronto, Toronto, ON

BACKGROUND: Congenital central hypoventilation syndrome (CCHS) is a genetic disorder affecting the PHOX2B gene characterized by alveolar hypoventilation. Our aim was to determine if there is a genotype-phenotype correlation between mutation type and ventilatory responses to exercise.
METHODS: Patients less than 18 years of age diagnosed with CCHS (PHOX2B positive) that had undergone a Stage 1 exercise test according to the Godfrey protocol, in the Cardiopulmonary Exercise Laboratory at the Hospital for Sick Children, in Toronto, Canada between September 2013 and March 2014 were included. The tests were performed on a Corival (Lode, BV, Netherlands) cycle ergometer with a VMAX V229 (VIASYS, CareFusion, San Diego, CA) oxygen consumption cart. A priori criteria for stopping the test included an end tidal $\mathrm{CO}_{2}$ of $55-60 \mathrm{mmHg}$, oxygen saturation of $85 \%$, cardiac arrhythmia, chest pain, or inability to maintain cycling cadence.

RESULTS: Eight children were included (4 female). Five (63\%) had a non polyalanine repeat mutation (NPARM). All three PARM mutations were 20/25. The median (IQR) age at the time of exercise testing was $10.1(8.3-12.9)$ years. Four children $(50 \%)$ presented within the first year of life. All participants are managed with nocturnal noninvasive positive pressure ventilation (NiPPV). Stage 1 exercise tests were abnormal in $2(25 \%)$ identical twin boys with 20/25 mutations whom presented in the first year of life. Their peak exercise end tidal $\mathrm{CO}_{2}$ values were $59 \mathrm{mmHg}$ and $53 \mathrm{mmHg}$. This represented a $48 \%$ and $25 \%$ respectively, increase at peak exercise as compared to baseline.

CONCLUSIONS: Ventilatory responses during Stage 1 exercise tests did not correlate with $\mathrm{PHOX} 2 \mathrm{~B}$ genotype or age of presentation in our cohort, suggesting the need for surveillance exercise testing in all children with CCHS. Further research is needed to determine whether there is any change in ventilatory responses to exercise over time. 


\section{A}

Abimaroun R.................... 32

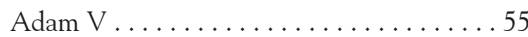

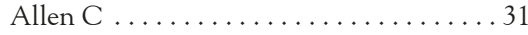

Amakye DO.................... 03

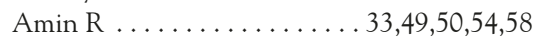

Angenedt $\mathrm{H}-\mathrm{W} \ldots \ldots \ldots \ldots \ldots \ldots .22$

Araujo T. . . . . . . . . . . . . . . . . . . 47,48

Arsenault A .................. 16

Avis M . ......................... 34

Azuma A ...................... 20

\section{B}

Bacon S .................... 42

Bacon SL . . . . . . . . . 01,02,04,06,07,15,16

Bailes Z. . . . . . . . . . . . . . . . . . . . 18

Barlett A ................... 28

Bateman E . . . . . . . . . . . . . . . 11

Beaucage D........................ 32

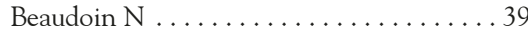

Bedi P. . . . . . . . . . . . . . . . . . . .52,53

Béland M ..................... 02

Bendiak $G \ldots \ldots \ldots \ldots \ldots \ldots \ldots . \ldots \ldots 2,53$

Bergeron C. . . . . . . . . . . . . . . . . . 05

Bernstein J ....................... 34

Berthiaume Y....................... 39

Bin-Hasan S. . . . . . . . . . . . . . . 33,50

Bismilla Z.................... 50

Bissonnette-Roy C................ 17

Blais L. . . . . . . . . . . . . . . . . . 04

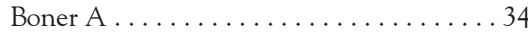

Boudreau M . . . . . . . . . . . . . . . . . 01,07

Bourbeau J . . . . . . . . . . . . . . . . . 08,32

Bouvet $G \ldots \ldots \ldots \ldots \ldots \ldots . \ldots . \ldots . \ldots 39$

Braganza M. . . . . . . . . . . . . . . . 30

Brahmendra A ...................21

Brawley L . . . . . . . . . . . . . . . . . . . . 43

Brooks D. . . . . . . . . . . . 13,28,41,45,47

Brosseau M. . . . . . . . . . . . . . . 08

Buhl R ..................... 11

Bujold A. .................... 26

Butcher S . . . . . . . . . . . . . . . 43

Byblow C..................... 51

\section{$\mathrm{C}$}

Cafazzo J..................... 28

Calverley PMA .................... 09

Cameron J . . . . . . . . . . . . . . . . . . . . . . . 46,48

Carignan S..................17,26

Caron M-A presenting on behalf of

E Hamelmann . . . . . . . . . . . . . . 34

Casaburi R ..................... 10

Castro-Codesal M . . . . . . . . . . . . . . .52,53

Chanez P . . . . . . . . . . . . . . . . . . . 09

Charbonneau C presenting on behalf of

H Magnussen ................... 09

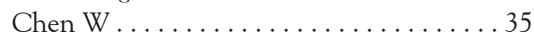

Choy J ......................22

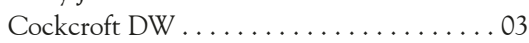

Collard HR. . . . . . . . . . . . . . . . . 18,20

Costabel U. . . . . . . . . . . . . . . . . . . 20

Cote N . . . . . . . . . . . . . . . . . . . . . 46

Cottin V.................... 18

Cox $G \ldots \ldots \ldots \ldots \ldots \ldots \ldots$

Coxson H. . . . . . . . . . . . . . . . . 08
D

Dahl R ......................... 09

Dale C . . . . . . . . . . . . . . . . . . . .54,56

Dance D..................... 46

Davies HE . . . . . . . . . . . . . . . . . 23

Davis BE. ...................... 03

Decramer M.................. 09

Dell S....................... 36

DeMars J.................... 40

Derom E...................... 11

Desveaux L. . . . . . . . . . . . . . . . . . . . . . . . . . . . . . . . . . .

Disse B ...................... 09

Downey K . . . . . . . . . . . . . . . 37

Dragomir AI.................... 04

Drouin I ..................... 32

Duckworth K .................. 42

\section{$\mathrm{E}$}

Elhalwi A.................... 01

Engel $M \ldots \ldots \ldots \ldots \ldots \ldots . \ldots . \ldots . \ldots$

\section{F}

Facchino $S \ldots \ldots \ldots \ldots \ldots \ldots \ldots$

Fan E ...................... 46

Faulds C.................... 28

Fell C ...................... 20

Fenton ME................... 27

Ferguson G.................. 11

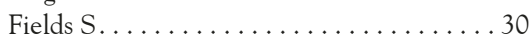

Finnigan H. . . . . . . . . . . . . . . . . 09

FitzGerald JM. . . . . . . . . . . . 14,35

Flannery J. . . . . . . . . . . . . . . . . 46

Fraser KL . . . . . . . . . . . . . . 57

\section{G}

Gage $W \ldots \ldots \ldots \ldots \ldots \ldots \ldots . \ldots 46$

Gagnon M . . . . . . . . . . . . . . . . . 24

Ganesh A..................... 30

Geisthoff $U$...................22

Gelberg J ...................... 25

Gershon A..................28

Gjevre JA.................... 27

Glennie J . . . . . . . . . . . . . . . . 28

Goldstein R . . . . . . . . . . . . .13,41

Goldstein RS . . . . . . . . . . . . . . . . . . 45

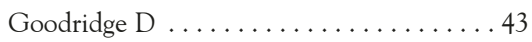

Groenke L . . . . . . . . . . . . . . . . 11

Guo L presenting on behalf of

F Maltais.................... 10

Gupta $S \ldots \ldots \ldots \ldots \ldots \ldots \ldots \ldots . \ldots 31$

\section{$\mathrm{H}$}

Hamilton A ..................10,11

Hanly PJ. . . . . . . . . . . . . . . . . . 51

Hansell DM . . . . . . . . . . . . . . . . . 18

Harkness H. . . . . . . . . . . . . . . . . 12

Harrison SL . . . . . . . . . . . . . . . . 13

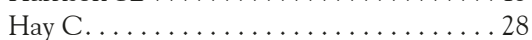

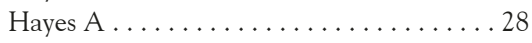

Herbert R..................... . 29

Herridge M. . . . . . . . . . . . . . . . . 46,48

Hillmer M . . . . . . . . . . . . . . . 28

Hollander Z . . . . . . . . . . . . . . . . . . 14

Horvey KJ.................... 43

Howie $L \ldots \ldots \ldots \ldots \ldots \ldots \ldots \ldots$

Huisman H. . . . . . . . . . . . . . . . 11

\section{I}

Iamonti VC . . . . . . . . . . . . . . . 44

Inoue $Y \ldots \ldots \ldots \ldots \ldots \ldots \ldots \ldots \ldots$

Iturri JBG ................. 10

\section{$\mathrm{J}$}

Jacob A. . . . . . . . . . . . . . . . . . . 06 Janaudis-Ferreira T. . . . . . . . . . . . . 44,47 Jenkins $H \ldots \ldots \ldots \ldots \ldots \ldots \ldots \ldots$ Jensen D.................... 08 Joubert A ................... 32

\section{K}

Kaminska M................... 55

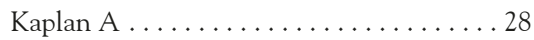

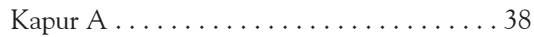

Katz S. . . . . . . . . . . 52,53,54

Kaye M....................... . . . . . . . . . . . .

Kelso J ....................... 49

Khakban R..................... . 14

Khan IS ..................... 21

Kim R....................... 36

King J . . . . . . . . . . . . . . . . . . . . . . . . . . . . . .

Kirsten A . ................................... 10

Korducki L . . . . . . . . . . . . . . . . . . . 11

\section{L}

Labossière V..................... 05 Laurin C. . . . . . . . . . . . . . . . . . . . 04,16

Lavoie A. ..................... 05

Lavoie K. . . . . . . . . . . . . . . 15,42

Lavoie KL. . . . . . . . . . . . . . 01,02,04,06,07,16

LeBlanc L. . . . . . . . . . . . . . . . . . . . 28

Lee AL . . . . . . . . . . . . . . . . . . . . . 45

Lefebvre J..................... 12

Leigh R. . . . . . . . . . . . . . . . . . . 30

Lemiere C. ...................... 01

Li P-Z .................... 32

Licskai C . . . . ............... 28

$\operatorname{Lim} A \ldots \ldots \ldots \ldots \ldots \ldots \ldots \ldots \ldots$

Lo $\mathrm{V} \ldots \ldots \ldots \ldots \ldots \ldots \ldots \ldots \ldots$

Lobchuk M. . . . . . . . . . . . . . . . . . . 29

Loewen AHS . . . . . . . . . . . . . . . . 57

Lopez-Hernandez L . . . . . . . . . . . . 48

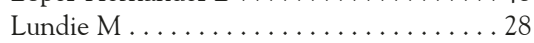

Lynd LD ................... 35

\section{M}

MacLean J . . . .................52,53 MacPherson A................... 31 Madeley C . . . . . . . . . . . . . . . . . . 28 Maghni K..................... 01 Maleki-Yazdi R................. 28 Maltais F. ................... 11 Mann H . . . . . . . . . . . . . . . . . . 22 Manns BJ ...................... 23

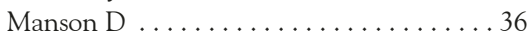
Marciniuk D..................... 43

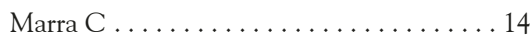

Marzolini S. ................. 47

Mateos D . . . . . . . . . . . . . . . . . . 49

Mathew R ........................................ 25

Mathur S . . . . . . . . . . . . . . . . . . 29, . . . . . . . 27

McCrae S.................... 27

McEvoy M..................... 29

McIntyre K. . . . . . . . . . . . . . . . . . . 28 
McKim D ................... .54,56

McManus B . . . . . . . . . . . . . . . . 14

Mehta R...................... 30

Mendes P . . . . . . . . . . . . . . . . . 46

Miller RF ..................... 23

Mishra EK ....................23

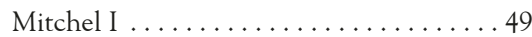

Moga A ..........................................

Moosa D. . . . . . . . . . . . . . . . . . . . 31

Moraes $\mathrm{T} \ldots \ldots \ldots \ldots \ldots \ldots \ldots \ldots . \ldots \ldots$

Moroni-Zentgraf P............... 34

Moullec G . . . . . . . . . . . . 04,16,42

Mullowney T ................... 36

\section{$\mathrm{N}$}

$\mathrm{Ng}$ R............................ 14

Nonoyama M. . . . . . . . . . . . 29, 29, 56

\section{$\mathrm{O}$}

Olfert JAP $\ldots \ldots \ldots \ldots \ldots \ldots \ldots \ldots .23$

Olmstead D . . . . . . . . . . . . . . .52,53

Ouellet I. . . . . . . . . . . . . . . . . . . . 32

\section{P}

Paine NJ....................... 16

Parshuram C. ................... 49

Patel H...................... . 49

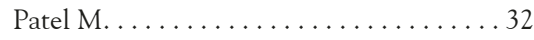

Patrick C . . . . . . . . . . . . . . . . 12

Pawlak B. ....................... 51

Pelletier R . . . . . ............................. 516

Pendharkar SR . . . . . . . . . . . . . . 51

Penz ED . . . . . . . . . . . . . . . . . . . 23

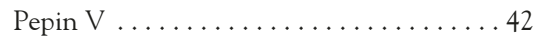

Pereira de Lima V ................. 44

Pizzichini E...................................... 11

Plaxton J .................... 28

Poirier CD ..................... 24

Prashar A ..................... 21

Pringle $\mathrm{J} \ldots \ldots \ldots \ldots \ldots \ldots \ldots \ldots . \ldots 28$

\section{$\mathbf{R}$}

Rabasa-Lhoret R ................... 39

Raddatz C. .................. 06
Raghu G. . . . . . . . . . . . . . . . 18

Rahman NM ................... 23

Rakovich G . . . . . . . . . . . . . 17,19,26

Reid J ....................... 11

Reppucci D. ................. 50

Richeldi L . . . . . . . . . . . . . . 18,20

Rimmer KP .................. 57

Rizk AK..................... 42

Road J. . . . . . . . . . . . . . . . . . .54,56

Robertson N. . . . . . . . . . . . . . . . . 13

Robles P . . . ................ 47

Rodriguez-Roisin R . . . . . . . . . . . . . 09

Rose $\mathrm{L} \ldots \ldots \ldots \ldots \ldots \ldots$. . . . . . . . . . . . . . . . . 44,56

Roy $M \ldots \ldots \ldots \ldots \ldots \ldots$

\section{S}

Sadatsavi M . . . . . . . . . . . . . . . . 14,35

Saunders N. . . . . . . . . . . . . . . . . . 50

Sayegh-Smith J . . . . . . . . . . . . 01,07

Schlenker-Herceg R. . . . . . . . . . . . . . 18

Schneiderman JE................ 58

Sedeno M. . . . . . . . . . . . . . . . . . 32

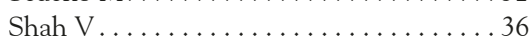

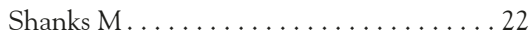

Sin D . . . . . . . . . . . . . . . . . . 14

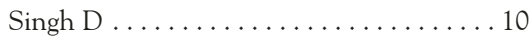

Sitzer N .......................25

Skomro RP.................... 27

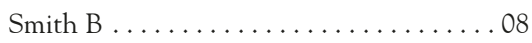

Smith MJ ................... 50

Smith WG ........................................... 37

Snow N ..................... 37

Souza-Barros L . . . . . . . . . . . . . . . . . . 48

Stephens D................... 36

Stewart SA................... 27

Stowasser S. . . . . . . . . . . . . . . . . . 20

Syed F. . . . . . . . . . . . . . . . . . 49

Sylviet-Carricart M .............. 05

\section{$\mathrm{T}$}

Tamari I . . . . . . . . . . . . . . . . . 31

Taniguchi H.................. 18

Terebiznik MR ................ 21
Tetzlaff K $09,10,11$

To WTH ..................... 58

Torres T ................... 46

Towse L . . . . . . . . . . . . . . . . . . . . . 09

Tremblay F................... 05

Troini R . . ................49,55

Tschoepe I . . . . . . . . . . . . . . . . . . . 20

Tye $R \ldots \ldots \ldots \ldots \ldots \ldots \ldots \ldots \ldots$

U

Unseld A . .................... 34

V

Vallée C-A..................... 26

Vandemoortele T.................24

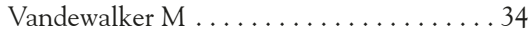

Vethanayagam D ................22

\section{W}

Waitere-Wijker S................ 11

Walker B ................... 40

Ward K...................... 51

Wardini R .................. 42

Warren J. . . . . . . . . . . . . . . . . . . . 51

Watz H. . . . . . . . . . . . . . . . . . .09,11

Weise S. ....................22

Wensley D ....................... 49

Wensley DF . . . . . . . . . . . . . . 38

Wouters EFM . . . . . . . . . . . . . . . . . 09

Wright MFA ................... 38

$\mathrm{Y}$

Yohannes A .................... 15

\section{$\mathrm{Z}$}

Zabjek K.................... 47

Zafari Z..................... 14

Zhao Y ...................... 10

Zhu PS .................... 24 


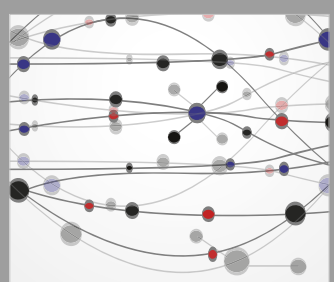

The Scientific World Journal
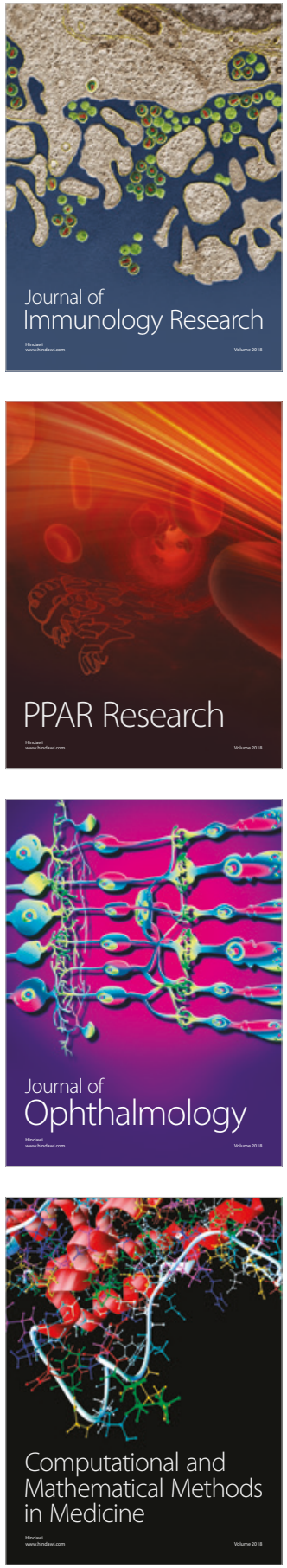

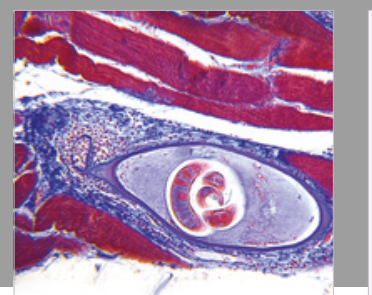

Gastroenterology Research and Practice

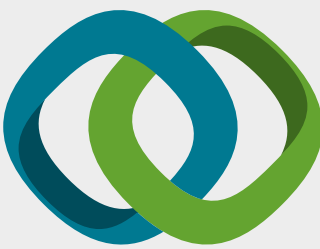

\section{Hindawi}

Submit your manuscripts at

www.hindawi.com
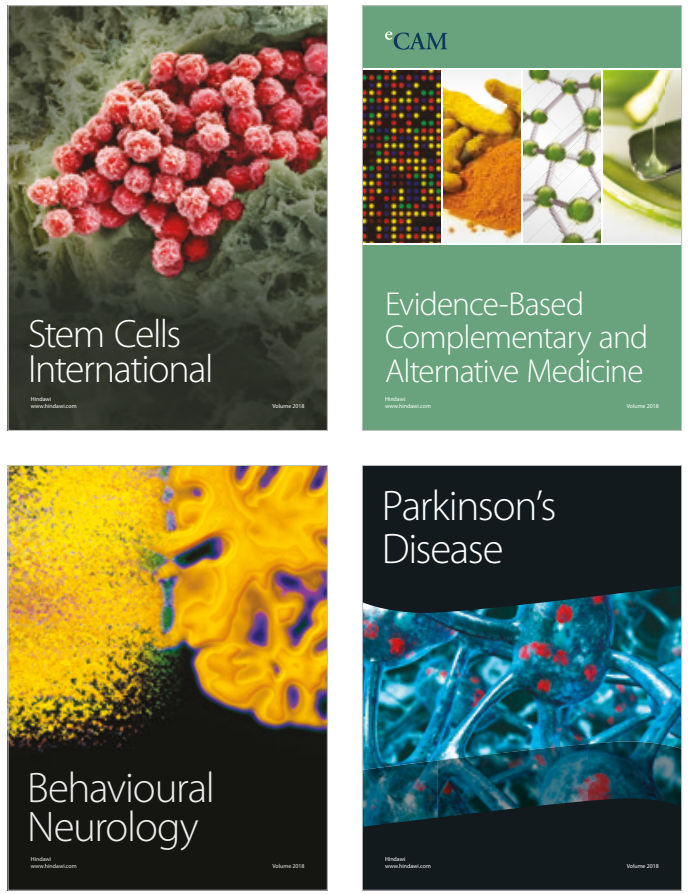

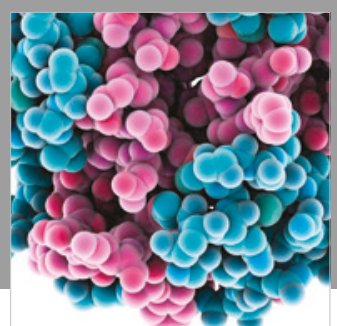

ournal of

Diabetes Research

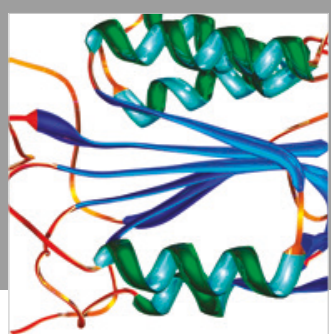

Disease Markers
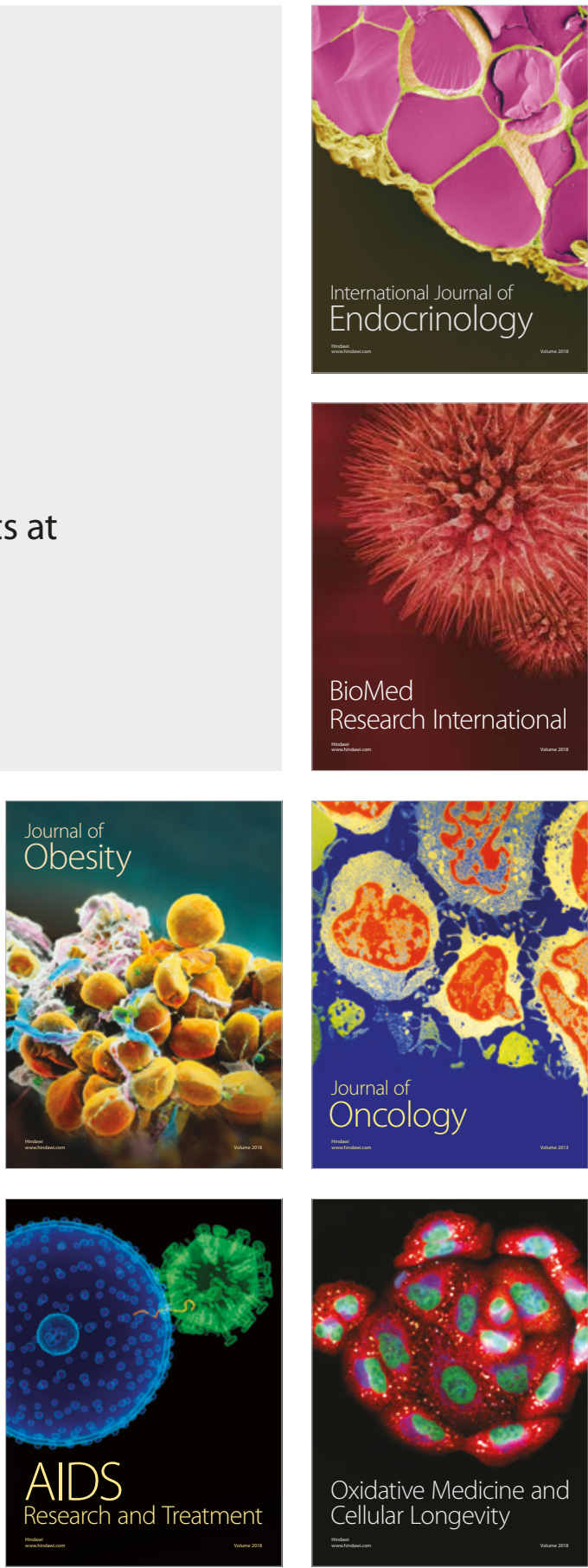